\title{
Kcns3 deficiency disrupts Parvalbumin neuron physiology in mouse prefrontal cortex: Implications for the pathophysiology of schizophrenia
}

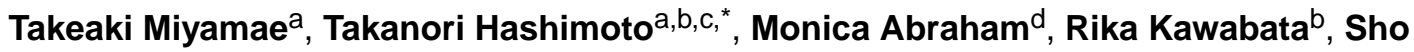 \\ Koshikizawa $^{b}$, Yufan Bian ${ }^{b}$, Yosuke Nishihata ${ }^{a}$, Mitsuru Kikuchi ${ }^{b, c}$, G. Bard Ermentrout ${ }^{d}$, \\ David A. Lewisa ${ }^{a}$, Guillermo Gonzalez-Burgos ${ }^{a},{ }^{*}$ \\ aTranslational Neuroscience Program, Department of Psychiatry, University of Pittsburgh School \\ of Medicine, Pittsburgh, PA 15213, USA \\ ${ }^{b}$ Department of Psychiatry and Behavioral Science, Kanazawa University Graduate School of \\ Medical Sciences, Kanazawa 920-8640, Japan \\ ${ }^{\mathrm{C}}$ Research Center for Child Mental Development, Kanazawa University, Kanazawa 920-8640, \\ Japan \\ ${ }^{\mathrm{d} D e p a r t m e n t}$ of Mathematics, Faculty of Arts and Sciences, University of Pittsburgh, Pittsburgh, \\ PA 15213, USA
}

\section{Abstract}

The unique fast spiking (FS) phenotype of cortical parvalbumin-positive (PV) neurons depends on the expression of multiple subtypes of voltage-gated potassium channels (Kv). PV neurons selectively express $K c n s 3$, the gene encoding Kv9.3 subunits, suggesting that Kcns3 expression is critical for the FS phenotype. KCNS3 expression is lower in PV neurons in the neocortex of subjects with schizophrenia, but the effects of this alteration are unclear, because Kv9.3 subunit function is poorly understood. Therefore, to assess the role of Kv9.3 subunits in PV neuron function, we combined gene expression analyses, computational modeling, and electrophysiology in acute slices from the cortex of Kcns3-deficient mice.

Kcns3 mRNA levels were $~ 50 \%$ lower in cortical PV neurons from Kcns3-deficient relative to wildtype mice. While silent per se, Kv9.3 subunits are believed to amplify the Kv2.1 current in Kv2.1-Kv9.3 channel complexes. Hence, to assess the consequences of reducing Kv9.3 levels, we simulated the effects of decreasing the Kv2.1- mediated current in a computational model. The FS cell model with reduced Kv2.1 produced spike trains with irregular inter-spike intervals, or stuttering, and greater $\mathrm{Na}^{+}$channel inactivation. As in the computational model, $\mathrm{PV}$ basket cells (PVBCs) from Kcns3-deficient mice displayed spike trains with strong stuttering, which depressed PVBC firing. Moreover, Kcns3 deficiency impaired the recruitment of PVBC firing at gamma

"Corresponding authors at: Translational Neuroscience Program, Department of Psychiatry, University of Pittsburgh School of Medicine, Pittsburgh, PA 15213, USA and Department of Psychiatry and Behavioral Science, Kanazawa University Graduate School of Medical Sciences, Kanazawa, Ishikawa 920-8640, Japan takanori@med.kanazawa-u.ac.jp (T. Hashimoto), gburgos@pitt.edu (G. Gonzalez-Burgos).

Appendix A. Supplementary data

Supplementary data to this article can be found online at https://doi.org/10.1016/j.nbd.2021.105382. 
frequency by stimuli mimicking synaptic input observed during cortical UP states. Our data indicate that Kv9.3 subunits are critical for PVBC physiology and suggest that KCNS3 deficiency in schizophrenia could impair PV neuron firing, possibly contributing to deficits in cortical gamma oscillations in the illness.

\section{Keywords}

Action potential; Basket cells; Gamma oscillations; Kv9.3

\section{Introduction}

Schizophrenia is characterized by significant impairments in core cognitive processes (Barch and Ceaser, 2012; Kahn and Keefe, 2013), such as working memory, that are thought to reflect, at least in part, disturbances in gamma oscillations (Uhlhaas and Singer, 2010). The production of gamma band oscillations is thought to depend on rhythmic synaptic inhibition (Buzsaki and Wang, 2012; Whittington et al., 2000), generated by parvalbumin-positive (PV) interneurons (Anto-noudiou et al., 2020; Chen et al., 2017; Sohal et al., 2009).

Moreover, in the neocortex of subjects with schizophrenia PV neurons display multiple alterations which suggest that the disturbance of gamma oscillations in this disorder is in part due to PV neuron dysfunction (Dienel and Lewis, 2019; Gonzalez-Burgos et al., 2015).

PV cells are a prominent subtype of cortical GABA neurons that, to produce inhibitory synaptic output, can discharge trains of narrow spikes at high and constant frequency, displaying their classical fast spiking (FS) phenotype (Hu et al., 2014; Kawaguchi and Kubota, 1997). The FS phenotype of PV neurons depends on the expression of voltagegated $\mathrm{K}^{+}$channel (Kv) subunits of the Kv3 subfamily (Du et al., 1996; Lau et al., 2000; Rudy and McBain, 2001). However, other Kv channels in addition to Kv3 likely contribute to the FS phenotype, since PV cells express multiple Kv subunit genes (Enwright et al., 2018; Okaty et al., 2009; Paul et al., 2017).

Interestingly, the variety of $\mathrm{Kv}$ channel genes expressed by PV neurons is highly conserved between mouse and human neocortex (Enwright et al., 2018; Krienen et al., 2020; Okaty et al., 2009). These and other similarities in voltage-gated channel gene expression are consistent with the findings showing that PV neurons from human neocortex display FS properties, as in mouse cortex (Stedehouder et al., 2019; Stedehouder et al., 2017; Szegedi et al., 2017; Szegedi et al., 2020; Wang et al., 2016).

Previously, we reported that in the human neocortex PV neurons selectively express $K C N S 3$, the gene encoding Kv9.3 subunits (Georgiev et al., 2012), suggesting that Kv9.3 subunits play a crucial role in PV neuron properties. However, the function of Kv9.3 subunits is poorly understood (Bocksteins, 2016; Rasmussen and Trimmer, 2018) and has not been investigated in PV cells. Kv9.3 subunits are members of the silent subfamily of Kv subunits, which cannot form homomeric channels and assemble into functional $\mathrm{Kv}$ channels only when combined with Kv2 subunits (Bocksteins, 2016; Rasmussen and Trimmer, 2018). Specifically, Kv9.3 subunits assemble with Kv2.1 to form Kv2.1-Kv9.3 heterotetramers (Bocksteins, 2016), which should be present in PV neurons, as they express Kcnb1, the gene 
encoding Kv2.1 subunits (Du et al., 1998; Enwright et al., 2018; Okaty et al., 2009; Paul et al., 2017).

Kv2.1-Kv9.3 channels exhibit different biophysical properties compared to homomeric Kv2.1 channels, including two times greater single channel conductance (Patel et al., 1997) and more hyperpolarized voltage dependence of activation (Kerschensteiner et al., 2003; Kerschensteiner and Stocker, 1999). The biophysical properties of Kv2.1- Kv9.3 channels suggest that, while silent per se, Kv9.3 subunits amplify the Kv2.1-mediated $\mathrm{K}^{+}$current (Bocksteins, 2016).

In previous studies, we reported that in the prefrontal cortex (PFC) of subjects with schizophrenia PV neurons express lower than normal levels of KCNS3 mRNA (Enwright et al., 2018; Georgiev et al., 2014). Kv channels produce hyperpolarizing currents and thus could decrease neuronal excitability. If so, KCNS3 downregulation in schizophrenia may tend to increase PV neuron firing, contributing to a homeostatic response to restore PV neuron activity in a hypoactive network (Arion et al., 2015). However, hyperpolarizing Kv2 currents could have complex effects and may facilitate, instead of decreasing, repetitive action potential firing (Guan et al., 2013; Romer et al., 2019). In such case, KCNS3 downregulation in schizophrenia, instead of homeostatically increasing the PV cell firing response, may disrupt the capacity of PV neurons to fire repetitively. Understanding the role that Kv9.3 subunits play in the FS phenotype of PV neurons is therefore crucial to develop hypotheses regarding the effects of KCNS3 deficiency on PV neurons and cortical circuit function in schizophrenia (Gonzalez-Burgos et al., 2015).

Using simulations in a computational model and experiments with PV neurons from Kcns3deficient mice, here we report that Kcns3 deficiency disrupts the FS phenotype of PV basket cells (PVBCs), depressing recruitment of PVBCs by natural patterns of synaptic input at gamma band frequency. These effects of Kcns3 deficiency on PVBC firing properties suggest that Kv9.3 subunits are crucial for the transformation of synaptic input into spike output by PVBCs, and that lower KCNS3 expression in schizophrenia could affect the recruitment of PV neurons by rhythmic excitatory input, possibly impairing the substrate of gamma oscillations.

\section{Materials and methods}

\subsection{Animals}

Animal procedures followed the guidelines of the National Institutes of Health Guide for Care and Use of Laboratory Animals, and the Fundamental Guidelines for Proper Conduct of Animal Experiment and Related Activities in Academic Research Institutions from the Ministry of Education, Culture, Sports, Science and Technology of Japan, as approved by the IACUCs of the University of Pittsburgh and Kanazawa University.

2.1.1. Mouse lines-To create mice with deficiency in Kcns 3 expression, a trapping cassette consisting of LacZ-reporter and neomycin-resistance genes, each containing a polyadenylation signal sequence at the end, was inserted into the intron immediately upstream the only protein-coding exon of the Kcns3 gene, by homologous recombination 
using the knockout first construct (CSD76140, Knockout Mouse Project Repository) to

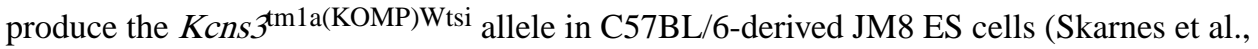
2011) (Fig. 1A). The chimeric mice with a germline transmission of Kcns $3^{\text {tmla(KOMP)Wtsi }}$ allele were crossed with C57BL/6 mice to obtain heterozygous mice (MMRRC_065425UCD).

G42 mice, which express green fluorescence protein (GFP) exclusively in PV neurons (Buchanan et al., 2012; Chattopadhyaya et al., 2004; Sippy and Yuste, 2013), were obtained from the Jackson Laboratory (stock No. 007677). The G42 line was generated by introducing a transgene consisting of regulatory and coding regions of the mouse Gad1 gene in which the first protein-coding exon was replaced by cDNA for enhanced GFP (Chattopadhyaya et al., 2004).

2.1.2. Breeding-We crossed heterozygous $K c n s 3^{\mathrm{tm} 1 \mathrm{a}(\mathrm{KOMP}) \mathrm{Wtsi}}$ mice to obtain wild type $\left(K c n s 3^{+/+}\right)$, heterozygous $\left(K c n s 3^{\text {neo/+ }}\right)$ and homozygous $\left(K c n s 3^{\text {neo/ neo }}\right)$ mice. In order to target PV neurons for electrophysiological recordings in acute slices, we crossed Kcns $3^{\text {neo/+ }}$ mice and $\mathrm{G} 42^{+/-}$mice (G42 mice that were heterozygous for the transgene). The resultant $\mathrm{G} 42^{+/-} ; K_{c n s} 3^{\text {neo/+ }}$ and $\mathrm{G} 42^{-/-} ; K_{c n s} 3^{\text {neo/+ }}$ mice were paired to produce Kcns3+/+, Kcns3neo/+ and Kcns3neo/neo mice with G42+/- or G42- /- genotypes. Then, $\mathrm{G} 42^{+/-} ; \mathrm{Kcns}^{3^{+/+}}$and $\mathrm{G} 42^{-/-} ; \mathrm{Kcns}^{+/++}$mice were bred to produce $\mathrm{G} 42^{+/-} ; \mathrm{Kcns}^{3^{+/+}}$ mice, and $\mathrm{G} 42^{+/-} ; K c n s 3^{\text {neo/neo }}$ and $\mathrm{G} 42^{-/-} ; K c n s 3^{\text {neo/neo }}$ mice were bred to produce $\mathrm{G} 42^{+/-} ; K c n s 3^{\text {neo/neo }}$ mice. These $\mathrm{G} 42^{+/-} ; K_{c n s} 3^{+/+}$and $\mathrm{G} 42^{+/-} ; K c n s 3^{\text {neo/neo }}$ mice are referred to as G42-Kcns $3^{+/+}$and G42-Kcns $3^{\text {neo/neo }}$ mice, respectively, and were used as control and Kcns3-deficient animals in the electrophysiology experiments.

The mean \pm SD postnatal age of mice in six experimental groups of wild type and Kcns3deficient animals was: 1) Gene expression analysis (Figs. 1, 2): $59 \pm 1.3$ days for all genotypes; 2) Intrinsic membrane properties (Fig. 5): G42-Kcns $3^{+/+}: 38 \pm 11$ days, G42Kcns $3^{\text {neo/neo }}: 33 \pm 9$ days; 3 ) Tests of the coefficient of variation of the inter spike intervals $\left(\mathrm{CV}_{\text {ISI }}\right.$ (Figs. 6 and 7): G42-Kcns $3^{+/+}: 40 \pm 8$ days, G42-Kcns3 $3^{\text {neo/neo }}: 34 \pm 9$ days; 4 ) Stimulation with UP states (Figs. 8 and 9): G42-Kcns $3^{+/+}: 30 \pm 6$ days, G42-Kcns $3^{\text {neo/neo: }}$ $32 \pm 6$ days; 5) Spontaneous excitatory postsynaptic potential (EPSP) recordings (Fig. 10): G42-Kcns $3^{+/+}: 32 \pm 2$ days, G42-Kcns $3^{\text {neo/neo }}: 34 \pm 3$ days. Given that the postnatal development of PV neurons in the PFC of wild type mice is complete by postnatal day 21 (Miyamae et al., 2017), all PV neurons have adult-like electrophysiological properties at the age range used in the currents experiments.

\subsection{Gene expression analysis}

2.2.1. Quantitative PCR (qPCR)-Gray matter tissue was dissected from the frontal cortex at the level of $+1.98 \mathrm{~mm}$ to $+1.70 \mathrm{~mm}$ from bregma from $\mathrm{Kcns}^{+/+}, \mathrm{Kcns}^{\text {neo/+ }}$, and $K c n s 3^{\text {neo/neo }}$ mice ( $n=5$ per genotype) and homogenized in TRIzol reagent (Invitrogen, Carlsbad, CA). Total RNA samples were prepared from the homogenates using RNeasy lipid tissue mini kit (Qiagen, Hilden, Germany) and converted into cDNA with High Capacity RNA-to- cDNA Kit (Applied Biosystems, Foster City, CA). The Kcns3 and Pvalb fragments were amplified with three internal control transcripts, beta- actin $(A c t b)$, cyclophilin A 
(Ppia) and glyceraldehyde-3-phosphate dehydrogenase (Gapdh), using Power SYBR Green PCR Master Mix and StepOnePlus real-time PCR system (Applied Biosystems). All primer sets (Table 1) amplified specific, single products with expected sizes and had amplification efficiency $296 \%$. Kcns3 and Pvalb mRNA levels were determined as $2^{\text {-dCT }}$ where dCT indicates the difference between cycle threshold (CT) of Kcns 3 or $P v a l b$ and the mean CT of the three control transcripts.

2.2.2. In situ hybridization (ISH)—Coronal sections of the frontal cortex $(12 \mu \mathrm{m})$ were cut from $+1.98 \mathrm{~mm}$ to $+1.54 \mathrm{~mm}$ from the bregma, and three sections evenly spaced at $\approx 130 \mu \mathrm{m}$ intervals were selected from each mouse $(\mathrm{n}=5$ per genotype $)$ and subjected to ISH for each mRNA of interest. Templates cDNA fragments for the synthesis of riboprobes were obtained by PCR using specific primer sets (Table 1) and subcloned into the plasmid pSTBlue-1 (Novagen, Madison, WI). Nucleotide sequencing revealed 100\% homologies of these fragments to the reported sequences in GenBank. Antisense and sense probes were transcribed in vitro in the presence of ${ }^{35} \mathrm{~S}-\mathrm{CTP}$ (PerkinElmer, Waltham, MA) for Kcns3 and Kcnb1 probes or in the presence of digoxigenin (DIG)-11-UTP (Roche, Mannheim, Germany) for Pvalb probe, using T7 or SP6 RNA polymerase (Promega, Madison, WI). All antisense riboprobes revealed distinctive signal distributions that were consistent with previous studies (Du et al., 1998; Georgiev et al., 2016) and Allen Brain Atlas (http://mouse.brain-map.org/). No signal beyond the background was detected with sense riboprobes for all mRNAs.

To detect Kcns3 and Kcnb1 mRNA levels in individual PV neurons, we performed duallabel ISH with ${ }^{35} \mathrm{~S}$-labeled riboprobe for $K c n s 3$ or $K c n b 1 \mathrm{mRNA}$ and DIG-labeled riboprobe for Pvalb mRNA. After fixation with $4 \%$ paraformaldehyde in phosphate-buffered saline (PBS), the sections were acetylated with $0.25 \%$ acetic anhydrate in $0.1 \mathrm{M}$ triethanolamine/ $0.9 \% \mathrm{NaCl}$ for $10 \mathrm{~min}$ and dehydrated through a graded ethanol series. The sections were then hybridized with ${ }^{35} \mathrm{~S}$-labeled riboprobes $\left(2 \times 10^{7} \mathrm{dpm} / \mathrm{ml}\right)$ for $K c n s 3$ or $K c n b 1$ and DIG-labeled riboprobe $(100 \mathrm{ng} / \mathrm{ml})$ for $P$ valb mRNA in hybridization buffer containing $50 \%$ formamide, $0.75 \mathrm{M} \mathrm{NaCl}, 20 \mathrm{mM}$ 1,4-piperazine diethane sulfonic acid, $\mathrm{pH} 6.8,10$ mM EDTA, $10 \%$ dextran sulfate, $5 \times$ Denhardt's solution $(0.2 \mathrm{mg} / \mathrm{ml}$ Ficoll, $0.2 \mathrm{mg} / \mathrm{ml}$ polyvinylpyrrolidone, $0.2 \mathrm{mg} / \mathrm{ml} \mathrm{BSA}$ ), $50 \mathrm{mM}$ dithiothreitol, $0.2 \% \mathrm{SDS}$, and $100 \mu \mathrm{g} / \mathrm{ml}$ yeast tRNA at $56{ }^{\circ} \mathrm{C}$ for $16 \mathrm{~h}$. The sections were washed in a solution containing $0.3 \mathrm{M}$ $\mathrm{NaCl}, 20 \mathrm{mM}$ Tris- $\mathrm{HCl}, \mathrm{pH} 8.0,1 \mathrm{mM}$ EDTA, $\mathrm{pH} \mathrm{8.0,} \mathrm{and} \mathrm{50 \%} \mathrm{formamide} \mathrm{at} 63{ }^{\circ} \mathrm{C}$, treated with $20 \mu \mathrm{g} / \mathrm{ml}$ RNase A (Sigma-Aldrich, St Louis, MO) at $37^{\circ} \mathrm{C}$, and washed in $0.1 \times \mathrm{SSC}(150 \mathrm{mM} \mathrm{NaCl}, 15 \mathrm{mM}$ sodium citrate $)$ at $66^{\circ} \mathrm{C}$. After the washing, sections were preincubated in Tris-buffered saline (TBS, $100 \mathrm{mM}$ Tris- $\mathrm{HCl}, \mathrm{pH} 7.5,150 \mathrm{mM} \mathrm{NaCl}$ ) with $3 \%$ bovine serum albumin (BSA) and $0.05 \%$ Triton X-100 for $30 \mathrm{~min}$, incubated with antiDIG antibody conjugated with alkaline phosphatase (Roche) diluted 1:2000 in TBS with 1\% BSA and $0.05 \%$ Triton X-100 for $12 \mathrm{~h}$ at $4{ }^{\circ} \mathrm{C}$, washed in TBS, and air dried. To detect Kcns 3 or Kcnb1 mRNA, sections were coated with NTB emulsion (Carestream, Rochester, $\mathrm{NY}$ ) diluted 1:1 with distilled water at $43{ }^{\circ} \mathrm{C}$, exposed for 1 week at $4{ }^{\circ} \mathrm{C}$, and developed with D-19 (Carestream). For the detection of Pvalb mRNA, sections were incubated in 0.5 $\mathrm{mg} / \mathrm{ml}$ nitroblue tetrazolium and $0.19 \mathrm{mg} / \mathrm{ml}$ bromo-chloroindolylphosphate (Roche) in 100 mM Tris- $\mathrm{HCl}, \mathrm{pH} 9.5,100 \mathrm{mM} \mathrm{NaCl}, 50 \mathrm{mM} \mathrm{MgCl}_{2}$ for $24 \mathrm{~h}$. 


\subsubsection{PV neuron sampling and quantification of gene expression in} individual PV neurons-For quantification of Kcns3 and Kcnb1 mRNA levels in PV neurons, the density of silver grains representing the expression of these mRNAs was

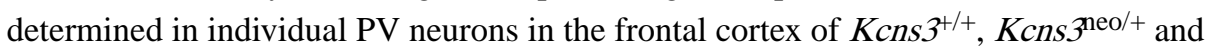
$K c n s 3^{\text {neo/neo }}$ mice ( $n=5$ per genotype). Using a microscope equipped with a motor-driven stage (Prior Scientific, Cambridge, UK) and the microcomputer imaging device (MCID) system (InterFocus Imaging, Cambridge, UK), sampling frames with a size of $200 \times 140$ $\mu \mathrm{m}$ were placed systematically and randomly in the region of interest (ROI) over the frontal cortex that included motor and primary sensory regions. In each frame, we counted the number of silver grains within the contour of individual PV neurons defined by alkaline phosphatase color reaction for Pvalb mRNA expression and calculated the raw density of silver grains per $100 \mu \mathrm{m}^{2} \mathrm{PV}$ neuron area. Three sections were analyzed for each mouse. In each section, mean background grain density (per $100 \mu \mathrm{m}^{2}$ ) was determined in gray matter regions devoid of a grain cluster or color reaction. The density of silver grains in individual PV neurons was determined by subtracting the background grain density from the raw grain density of individual PV neurons sampled in the same section. For Kcns3 mRNA, $108 \pm 15,96 \pm 8.3$ and $104 \pm 17 \mathrm{PV}$ neurons per mouse were analyzed in $\mathrm{Kcns}^{+/++}$, $K c n s 3^{\text {neo/+ }}$ and Kcns $3^{\text {neo/neo }}$ mice, respectively. For Kcnb1 mRNA, 79 $\pm 18,85 \pm 18$ and 81 $\pm 16 \mathrm{PV}$ neurons per mouse were analyzed in $\mathrm{Kcns}^{{ }^{+/+}}, \mathrm{Kcns}^{\text {neo/+ }}$ and $\mathrm{Kcns} 3^{\text {neo/neo }}$ mice, respectively.

\subsection{Computational modeling}

A Hodgkin-Huxley type computer model of a fast-spiking (FS) neuron was implemented using XPP software (http://www.math.pitt.edu/ bard/xpp/xpp.html). As in our previous study of FS cell models sodium current based on equations published by Fleidervish and col(Ermentrout and Wechselberger, 2009), the model used for the simu-leagues (Fleidervish et al., 1996). Second, we added an additional polations here was based on Erisir et al., 1999 (Erisir et al., 1999) with tassium conductance to model the Kv2.1 channel, $\mathrm{g}_{\mathrm{Kv} 2}$. Third, we set to several modifications. First, we included a slow inactivation of the 0 the slow potassium channel conductance, corresponding to the Kv1.3 conductance of Erisir 1999, which produces a complex dynamics due to the presence of a canard structure (Ermentrout and Wechselberger, 2009), which may confound the analysis of the effects of Kcns3 deficiency in the model. Hence, the Kv conductances in our current model are the Kv3.1 as in Erisir 1999, plus $\mathrm{g}_{\mathrm{Kv} 2}$ added to assess the effects of Kcns3 deficiency. We also added a Gaussian white noise term to the voltage to mimic intrinsic noise in the physiological preparation. For completeness, below we include the full set of equations:

$$
\begin{gathered}
0.1 v^{\prime}=I(t)-0.041(v+70)-15 m^{3} h s(v-55)-\left(4 n^{2}+g_{K v 2} q^{2}\right)(v+97)+\sigma W(t) \\
x^{\prime}=a_{x}(v)(1-x)-b_{x}(v) x, x \in\{m, h, n, s\} \\
q^{\prime}=(1 /(1+\exp (-(v+3.8) / 8))-q)\left(a_{n}(v)+b_{n}(v)\right)
\end{gathered}
$$




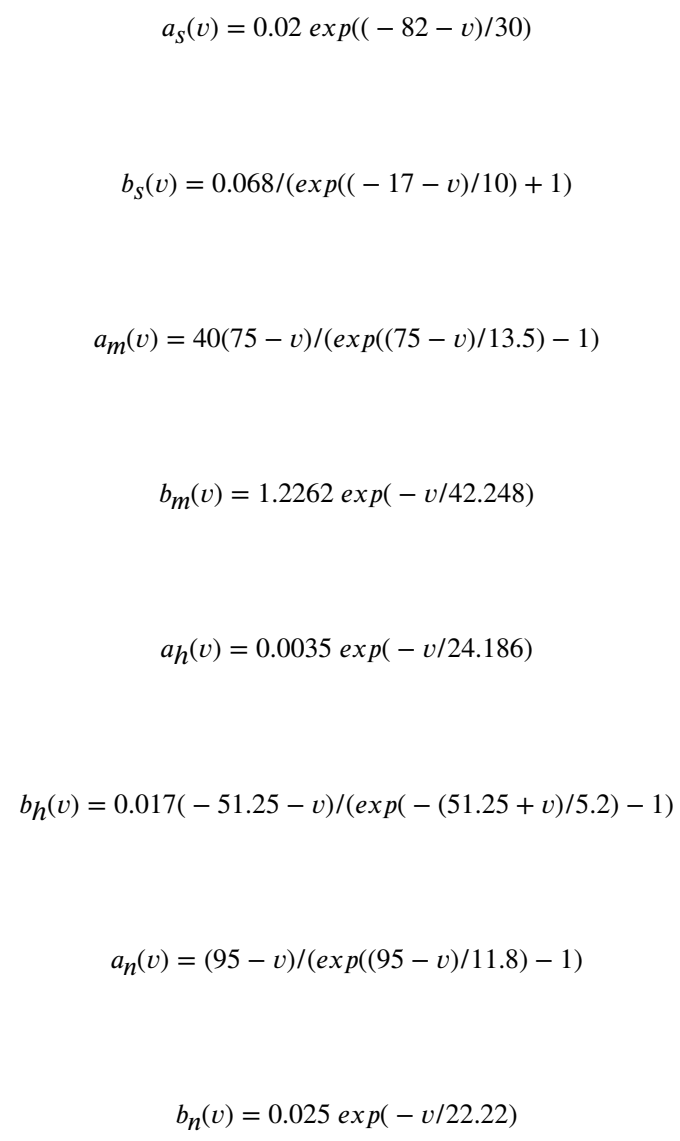

$\mathrm{I}(\mathrm{t})$ is a step function of current with various values as given in Fig. 5. Similarly, the noise amplitude, $\sigma$, and the $\mathrm{Kv} 2$ conductance, $\mathrm{g}_{\mathrm{Kv} 2}$, also varied. $\mathrm{W}(\mathrm{t})$ is a white noise increment. $m, h$ and $s$ are the activation $(\mathrm{m})$ and inactivation $(\mathrm{h}, \mathrm{s})$ gating variables for the $\mathrm{Na}^{+}$ conductance, and $n$ and $q$ are the activation gate variables for the Kv conductances.

\subsection{Brain slice preparation and electrophysiology}

Solutions employed-Slicing solution (in $\mathrm{mM}$ ): sucrose 210, $\mathrm{NaCl} 10, \mathrm{KCl} 1.9$, $\mathrm{Na}_{2} \mathrm{HPO}_{4}$ 1.2, $\mathrm{NaHCO}_{3}, \mathrm{MgCl}_{2} 6, \mathrm{CaCl}_{2}$ 0.5, glucose 10, $\mathrm{pH}$ 7.3-7.4 when bubbled with $95 \% \mathrm{O}_{2}-5 \% \mathrm{CO}_{2}$.

Artificial Cerebro Spinal Fluid (ACSF, in mM): $\mathrm{NaCl} 125, \mathrm{KCl} 2.5, \mathrm{Na}_{2} \mathrm{HPO}_{4} 1.25$, glucose 10, $\mathrm{NaHCO}_{3} 25, \mathrm{MgCl}_{2} 1$ and $\mathrm{CaCl}_{2}$ 2, $\mathrm{pH}$ 7.3-7.4, bubbled with $95 \% \mathrm{O}_{2}-5 \% \mathrm{CO}_{2}$.

ACSF modified to induce UP states (in mM): $\mathrm{NaCl} 125, \mathrm{KCl} 3.5, \mathrm{Na}_{2} \mathrm{HPO}_{4} 1.25$, glucose $10, \mathrm{NaHCO}_{3} 25, \mathrm{MgCl}_{2} 1$ and $\mathrm{CaCl}_{2}$ 1, $\mathrm{pH} 7.3-7.4$, bubbled with $95 \% \mathrm{O}_{2}-5 \% \mathrm{CO}_{2}$.

Potassium Gluconate (in mM): KGluconate 120, KCl 10, HEPES 10, EGTA 0.2, MgATP 4.5, NaGTP 0.3, sodium phosphocreatine 14, $\mathrm{pH} 7.2-7.4$. 
2.4.1. Brain slice preparation-Acute slices were prepared as described previously (Miyamae et al., 2017). Briefly, coronal slices $(300 \mu \mathrm{m})$ were cut from the frontal cortex in ice-cold slicing solution. After cutting, slices were incubated at room temperature in ACSF. For recording, slices were submerged in a chamber superfused with oxygenated ACSF (2-3 $\mathrm{ml} / \mathrm{min}, 30-32{ }^{\circ} \mathrm{C}$ ) in the presence of the AMPA receptor antagonist cyanquixaline (CNQX) $(10 \mu \mathrm{M})$ and the $\mathrm{GABA}_{\mathrm{A}}$ receptor antagonist gabazine $(10 \mu \mathrm{M})$ when recording intrinsic membrane properties and during UP state stimulation. To record sEPSPs, the GABA receptor antagonist gabazine $(10 \mu \mathrm{M})$, was added.

2.4.2. Electrophysiology-Whole-cell current clamp recordings were obtained from PV neurons identified by GFP fluorescence in layers 2 to 5, using microscopes (Zeiss Axioskop FS; Olympus BX51) equipped with epifluorescence, infrared illumination, differential interference contrast, and CCD video cameras (EXi Aqua, Q-Imaging, AZ). Glass pipettes (3-5 M $\Omega$ ) were filled with Potassium Gluconate solution containing biocytin $(0.4 \%)$ freshly added to the pipette solution for later identification of the PV cell morphology. For whole-cell current clamp recordings, we used Multiclamp 700A/B amplifiers (Axon Instruments, CA) with low-pass filtering at $4 \mathrm{kHz}$, and digitizing at 10/20 kHz using Power 1401 digital-analog converter and the Signal 5 software (Cambridge Electronic Design, CED, Cambridge, UK). After recordings, the slices were immersed in 4\% paraformaldehyde in $0.1 \mathrm{M}$ PBS for $24-72 \mathrm{~h}$ at $4{ }^{\circ} \mathrm{C}$ and were subject to diaminobenzidinebased processing to visualize the biocytin for reconstruction of the morphology of the recorded neurons using Neurolucida (MBF Bioscience, VT) (Miyamae et al., 2017).

\subsubsection{Injection of rectangular current steps-During current injection} experiments, the series resistance and pipette capacitance were monitored and cancelled using bridge balance and capacitance neutralization circuits in the Multiclamp amplifiers (Axon Instruments). Families of rectangular $500 \mathrm{~ms}$ current pulses were applied in 10 pA increments, starting at $-50 \mathrm{pA}$ and repeating each step amplitude 2-3 times at 0.2 Hz. The following intrinsic membrane properties were measured from each PV cell: RMP, action potential (AP) voltage threshold, AP current threshold or rheobase, AP amplitude, AP half width, first AP delay, afterhyperpolarization, input resistance (Rin), slope of the frequency-current plot (f-I slope) and membrane time constant, as described previously (Miyamae et al., 2017). The rheobase was estimated as the smallest depolarizing current step amplitude that elicited at least one AP in each repetition of that particular step amplitude. Spike frequency adaptation was estimated calculating the ratio between the last and first inter-spike intervals (ISIs) in each spike train, or ISI $_{\text {ratio }}=$ ISI(n)/ISI(1). The variability of firing was measured by the coefficient of variation of the ISIs $\left(\mathrm{CV}_{\text {ISI }}\right)$, i.e. the standard deviation (SD) of the ISIs divided by their mean. The $\mathrm{CV}_{\text {ISI }}$ was estimated in the spike trains evoked by each current step amplitude. The analysis of ISIs was performed using scripts written in Signal 5 (CED) and OriginPro (OriginLab, MA) software packages. For the $\mathrm{CV}_{\text {ISI }}$, the data are expressed as a function of current above the threshold level that produced at least three spikes, which in many individual cells was higher than the rheobase.

2.4.4. Injection of UP state-like currents-To assess the effects of Kcns 3 deficiency on the spike output elicited by natural patterns of stimuli, we injected into PV neurons 
depolarizing current mimicking the time course and amplitude of synaptic input observed during UP states. First, UP states were induced in acute slices from the PFC of G42 mice by perfusing the recording chamber with modified ACSF at a high flow rate $(8-12 \mathrm{ml} / \mathrm{min})$ (Sanchez-Vives and McCormick, 2000). Under these conditions, UP states developed in PFC cells within a few minutes of the perfusion (Sanchez-Vives and McCormick, 2000). Then, synaptic input during a sequence of 3 subthreshold UP states $\left(\mathrm{UP}_{(1)}, \mathrm{UP}_{(2)}\right.$ and $\left.\mathrm{UP}_{(3)}\right)$ was recorded from an individual neuron and digitally stored. The time course and amplitude pattern of synaptic input during these 3 UP states was used in current clamp experiments to inject depolarizing current into PV neurons via the recording electrode, reproducing the changes in membrane potential observed during the UP states.

As the recorded UP states were subthreshold, firing was elicited by increasing the mean current injected during $\mathrm{UP}_{(1)}$ in increments of $10 \mathrm{pA}$, which resulted in increments of 7 and $8 \mathrm{pA}$ of the mean current injected during $\mathrm{UP}_{(2)}$ and $\mathrm{UP}_{(3)}$, respectively. The smallest injected current that elicited spikes during $\mathrm{UP}_{(1)}$ was defined as the stimulus strength 1, or threshold. Thereafter, 3 additional increments were applied to a total of 4 stimulus strengths. Each stimulus strength was repeated in 10 trials (intertrial interval $=5 \mathrm{~s}$ ). The spike probability, $\mathrm{p}$ (spike), was estimated across the duration of each UP state in $2 \mathrm{~ms}$ bins. The $\mathrm{p}$ (spike) was calculated as: $p($ spike $)=$ number of trials with spikes $/ 10$, where 10 is the total number of trials per stimulus strength. The analysis of spike output during UP state stimulation was performed using scripts written in Signal 5 (CED) and OriginPro (OriginLab) software packages.

\subsection{Spontaneous excitatory postsynaptic potentials (sEPSPs)}

We recorded sEPSPs in the presence of gabazine $(10 \mu \mathrm{M})$ at the cell's resting membrane potential (RMP) for 3-5 min, and 100-200 sEPSPs were detected for each PV neuron using MiniAnalysis software (Synaptosoft, GA). For the analysis of large sEPSPs from the recording, we selected all the sEPSPs with peak amplitude larger than a threshold of 1 $\mathrm{mV}$. The sEPSP amplitude reported for each neuron is the average of the amplitudes of all the sEPSPs detected in each cell. The decay kinetics was quantified on the average sEPSP waveform obtained for each cell by fitting a double exponential decay function and computing a weighted decay time constant ( $\tau \mathrm{w}$ ) as follows (Rotaru et al., 2011): $\tau \mathrm{w}=$ $\left[\left(\mathrm{A}_{\text {slow }} \times \tau_{\text {slow }}\right)+\left(\mathrm{A}_{\text {fast }} \times \tau_{\text {fast }}\right)\right] /\left(\mathrm{A}_{\text {slow }}+\mathrm{A}_{\text {fast }}\right)$, where $\mathrm{A}_{\text {slow }}, \mathrm{A}_{\text {fast }}, \tau_{\text {slow }}, \tau_{\text {fast }}$ are the amplitude and time constants of slow and fast EPSP decay components.

Tetraethylammonium (TEA) was dissolved in ACSF at the final concentration (10 mM) and bath-applied for $10 \mathrm{~min}$. TEA and all other chemical reagents were obtained from Sigma-Aldrich (MO).

\subsection{Statistical analysis}

The data are expressed as mean \pm SD unless otherwise indicated. Analysis was performed using SPSS 25 (IBM, NY). ISH data: One-way ANOVA followed by Tukey's test were used to compare Kcns3 and Kcnb1 mRNA levels in PV neurons across genotypes. Electrophysiology data: The normality of data distribution was tested on the residuals of the data using Shapiro Wilk tests and was verified by using the D'Agostino K-squared 
test, in every case both normality tests produced identical results. When Shapiro-Wilk tests implemented on the residuals of the data rejected normality, the tests were repeated on the residuals of the Ln-transformed data (Miyamae et al., 2017). The differences between groups were assessed using Student's $t$-test and paired samples $t$-test. Nonparametric MannWhitney's or Wilcoxon Signed Rank tests were performed on the original data if normality was rejected after Ln transformation. Shapiro Wilk tests with $p<0.05$ are indicated in the Figure legends.

\section{Results}

\subsection{In Kcns $3^{\text {neo/neo }}$ mice, PV neurons show Kcns3 downregulation with unaltered Kcnb1 expression}

To assess the extent to which Kcns 3 expression is affected by the insertion of the trapping cassette in our mouse line (Fig. 1A), we performed qPCR using RNA isolated from the frontal cortex. The expression of the Kcns3 gene in mouse cortex increases during early postnatal development, from undetectable levels at postnatal day 7 to adult-like levels by postnatal day 25 (Okaty et al., 2009). The mice employed in the current experiments had ages between 30 and 60 postnatal days (see Methods), a range when PV neurons in the mouse frontal cortex display mature electrophysiological and morphological properties (Miyamae et al., 2017). It is possible, importantly, that any changes in PV neuron properties observed at postnatal days 30-60 are due at least in part to effects of Kcns3 downregulation during early postnatal development, when transcriptional, electrophysiological and morphological maturation of PV neurons takes place (Miyamae et al., 2017; Okaty et al., 2009).

As shown in Fig. 1B, using qPCR we found that, relative to $K c n s 3^{+/+}$mice, $K c n s 3$ mRNA levels were lower by $26 \%$ and $45 \%$ in $K c n s 3^{\text {neo/+ }}$ and $K c n s 3^{\text {neo/neo }}$ mice, respectively (One-Way ANOVA, $\mathrm{F}_{(2,12)}=82.5, p=9.8 \times 10^{-8}$ ). We also quantified Pvalb mRNA levels, which have been proposed to reflect levels of PV neuron activity (Carder et al., 1996; Cohen et al., 2016; Donato et al., 2013). However, we found that Pvalb mRNA levels in the frontal cortex were not different among $\mathrm{Kcns}^{+/+}(0.078 \pm 0.006), \mathrm{Kcns}^{3^{\text {neo/+ }}}(0.072 \pm 0.008)$ and $K c n s 3^{\text {neo/neo }}(0.078 \pm 0.007)$ mice (One-Way ANOVA, $\left.\mathrm{F}_{(2,12)}=0.956, p=0.411\right)$.

Next, to examine the effects of the genetic manipulation on Kcns 3 expression in individual PV neurons, we performed dual-label ISH (Fig. 2A) to quantify Kcns 3 mRNA grain density in individual $P$ valb mRNA-positive cells that were systematically and randomly sampled in the frontal cortex of $\mathrm{Kcns} 3^{+/+}, \mathrm{Kcns} 3^{\text {neo/+ }}$ and $\mathrm{Kcns} \mathrm{3}^{\text {neo/neo }}$ mice. The mean density of Kcns 3 mRNA grains per PV neuron was decreased by $21 \%$ and $53 \%$ in $K c n s 3^{\text {neo/+ }}$ and $K c n s 3^{\text {neo/neo }}$ mice, respectively, relative to $K c n s 3^{{ }^{+/+}}$mice (Fig. 2B). To assess the heterogeneity of the decrease in Kcns 3 gene expression per cell, we examined the distribution of Kcns 3 mRNA grain densities per individual PV neuron, and found that the distributions were left-shifted in both $K c n s 3^{\text {neo/neo }}$ and $K c n s 3^{\text {neo/+ }}$ relative to $\mathrm{Kcns}^{3^{+/+}}$mice (Fig. 2C).

Given that the main role hypothesized for Kv9.3 subunits is amplifying the Kv2.1 current, one possibility is that Kcns 3 deficiency, by decreasing Kv2.1 amplification, 
causes compensatory upregulation of the expression of $K c n b 1$, the gene encoding Kv2.1 subunits. $K c n b 1$ is ubiquitously expressed by cortical neurons, including a large fraction of PV neurons (Du et al., 1998) (Allen Brain Atlas, https://celltypes.brain-map.org/ rnaseq\#transcriptomics). Using dual-label ISH to assess Kcnb1 mRNA levels in Pvalb mRNA-positive cells, we found that $K c n b 1$ mRNA levels in PV neurons did not differ among $\mathrm{Kcns}^{+/ /+}$, Kcns $3^{\text {neo/+ }}$ and $K c n s 3^{\text {neo/neo }}$ mice (Fig. 2D, E), suggesting an absence of compensatory upregulation of Kv2.1 subunits in response to Kcns 3 deficiency. The ISH data therefore suggest in our line of Kcns3 deficient mice, the decrease in Kcns3 mRNA levels is not accompanied by changes in Kcnb1 mRNA levels. Hence, in our mouse line, the expected effects of Kcns3 deficiency on the FS phenotype of PV neurons should be derived from a partial loss of Kv9.3-mediated amplification of Kv2.1 current.

\subsection{Kv2.1 deficiency alters repetitive firing in a computational model of FS neurons}

Previous studies suggested that Kv2.1 channels regulate repetitive firing. For example, in layer 3 pyramidal cells and spinal motoneurons, Kv2.1 currents facilitate repetitive firing by preventing $\mathrm{Na}^{+}$channel inactivation (Guan et al., 2013; Romer et al., 2019). The FS phenotype of PV neurons, however, differs significantly from the firing patterns of pyramidal cells or motoneurons. Hence, to prove the concept that Kv2.1 currents regulate repetitive firing in PV neurons, we used a computational model of FS cells to simulate the effects of reducing the $\mathrm{Kv} 2.1$ conductance, which is the expected consequence from a loss of Kv9.3- mediated amplification of Kv2.1 current with Kcns3 deficiency. For the simulations, as in our previous modeling studies of PV cells (Ermentrout and Wechselberger, 2009), we used a well-known Hodgkin- Huxley type model of FS cells (Erisir et al., 1999), modified by adding the $\mathrm{Kv}$ conductance $\mathrm{g}_{\mathrm{Kv} 2}$, to simulate the $\mathrm{Kv} 2.1$ current, and a slow inactivation component to the voltage-gated $\mathrm{Na}^{+}$conductance (Martina and Jonas, 1997) using previously published parameters (Fleidervish et al., 1996). Application of excitatory current to the FS cell model with intact $\mathrm{g}_{\mathrm{Kv} 2}$ produced spike trains with the continuous firing typical of the FS phenotype (Goldberg et al., 2008) (Fig. 3A). In contrast, in the FS cell model with reduced $\mathrm{g}_{\mathrm{Kv} 2}$ levels, during application of stimulus near the current threshold, or rheobase, repetitive firing was interrupted by silent periods in the continuous presence of excitatory current (Fig. 3B). During these prolonged inter-spike intervals (ISIs), the FS cell model entered a subthreshold state, as reported previously (Ermentrout and Wechselberger, 2009; Golomb et al., 2007). This irregularity of FS cell firing near rheobase current is typically observed experimentally in some FS neurons and was previously termed stuttering (Descalzo et al., 2005; Goldberg et al., 2008; Helm et al., 2013; Markram et al., 2004; Povysheva et al., 2008).

To quantify the irregularity of firing, we calculated the coefficient of variation of the ISIs ( $\left.\mathrm{CV}_{\text {ISI }}\right)$ in the spike trains (Helm et al., 2013; Povysheva et al., 2008). In the FS cell model with intact $\mathrm{g}_{\mathrm{Kv} 2}$, the $\mathrm{CV}_{\mathrm{ISI}}$ diminished sharply as the applied current increased just above threshold (Fig. 3C). In contrast, in the FS model with reduced $\mathrm{g}_{\mathrm{Kv} 2}$, larger applied currents were necessary to decrease stuttering and the $\mathrm{CV}_{\text {ISI }}$ (Fig. 3C). Moreover, the $\mathrm{CV}_{\text {ISI }}$ decreased with increasing $\mathrm{g}_{\mathrm{Kv} 2}$ levels (Fig. 3C,D), supporting the idea that Kv2.1 currents facilitate repetitive firing, thus preventing stuttering. 
In other types of neurons, Kv2.1 currents facilitate repetitive firing by reducing $\mathrm{Na}^{+}$ channel inactivation (Guan et al., 2013; Romer et al., 2019). Hence, one possibility is that reduced levels of $\mathrm{Kv} 2.1$ conductance increase $\mathrm{Na}^{+}$channel inactivation, causing the FS cell to become temporarily refractory, thus contributing to the strong stuttering phenotype. Therefore, next we examined if stuttering is associated with $\mathrm{Na}^{+}$channel inactivation. In the FS model with intact $\mathrm{g}_{\mathrm{Kv} 2}$, during repetitive firing the $\mathrm{Na}^{+}$conductance consistently inactivated during each spike, as indicated by downward shifts in the value of the inactivation gates $\mathrm{s}$ and $\mathrm{h}$ (Fig. 3A, E), and recovered rapidly from inactivation during each ISI (Fig. 3E). In the FS cell model with reduced $\mathrm{g}_{\mathrm{Kv} 2}$, the inactivation of the $\mathrm{Na}^{+}$ conductance with each spike was stronger, as revealed by a greater reduction in $\mathrm{s}$ and $\mathrm{h}$ values (Fig. 3F). Moreover, during successive spikes the $\mathrm{Na}^{+}$channel inactivation summated until the FS cell model with reduced $\mathrm{g}_{\mathrm{Kv} 2}$ became refractory (Fig. 3B, F). Once the $\mathrm{Na}^{+}$ conductance recovered from inactivation, the FS cell model resumed firing, producing the long ISIs characteristic of stuttering (Fig. 3B, F). Our simulations therefore suggest that Kv2.1 currents enhance repetitive firing in FS cells by facilitating the recovery of $\mathrm{Na}^{+}$channels from voltage-dependent inactivation. Hence, the loss of $\mathrm{g}_{\mathrm{Kv} 2}$ may produce stuttering secondary to enhanced and prolonged inactivation of $\mathrm{Na}^{+}$channels.

The exact mechanisms by which $\mathrm{Kv} 2$ deficiency increased $\mathrm{Na}^{+}$channel inactivation remain to be investigated fully, however our simulations suggested that a reduction in amplitude of the afterhyperpolarization associated with each action potential during repetitive firing (Fig. 3 A,B, and Supplemental Fig. 1) may contribute to the changes in firing properties of the FS model.

\subsection{Kcns3 deficiency alters repetitive firing in PVBCs}

The results of our simulations in the FS cell model suggest that if Kcns3 deficiency decreases the Kv9.3-mediated amplification of the Kv2.1 current in PV neurons, it should increase stuttering. To test the predictions from the simulations, we assessed the firing properties of PV neurons in acute slices from the PFC of G42- $\mathrm{Kcns}^{+/+}$and G42$K c n s 3^{\text {neo/neo }}$ mice.

To this aim, we obtained current clamp recordings from PV neurons in layers 2-5 of acute brain slices prepared from the PFC of G42- $\mathrm{Kcns}^{3^{+/+}}$and G42-Kcns $3^{\text {neo/neo }}$ mice. The recorded PV neurons were filled with biocytin to assess their morphology after the experiments. Neuronal reconstructions showed that the majority of the recorded PV neurons (92.5\%) were basket cells (PVBCs), illustrated by the examples in Fig. 4A,B. A minority (7.5\%) of the recorded PV neurons were not PVBCs and had morphology typical of chandelier cells (Supplemental Fig. 2), with cell bodies exclusively localized near the border between layers 1 and 2, as in our previous studies (Miyamae et al., 2017; Tikhonova et al., 2018). Given the small number of chandelier cells in our database (G42- $\mathrm{Kcns}^{+/+}, n=5$ cells; G42-Kcns $3^{\text {neo/neo }}, n=8$ cells), statistical tests lacked sufficient power to assess the effects of Kcns3 deficiency on chandelier cells (Supplemental Fig. 2). Hence, our analysis was focused on the PVBCs (G42-Kcns $3^{+/+}, n=93$; G42-Kcns $\left.3^{\text {neo/neo }}, n=80\right)$.

Given that Kcns3 expression is normally upregulated during the postnatal period when PVBC morphology achieves mature state (Miyamae et al., 2017) we assessed whether 
Kcns3 deficiency affects PV neuron morphology. To this aim, we digitally reconstructed PVBC dendrites and axons (Fig. 4A,B), and performed quantitative morphometry analysis (G42-Kcns $3^{+/+}, \mathrm{n}=8$ cells from 5 mice; G42- Kcns $3^{\text {neo/neo }}, \mathrm{n}=8$ cells from 5 mice). Our data showed that neither the total length of the dendritic tree (Fig. 4C) nor axonal arbor (Fig. 4D) differed by genotype. Sholl analysis showed a trend for greater length and branching complexity in the proximal compartments of the dendrites and axon of PVBCs from Kcns3deficient mice (Fig. 4E,F), but these differences did not achieve statistical significance. Hence, our data suggest that Kcns3 deficiency does not affect PVBC morphology.

We assessed the general membrane properties of PVBCs, which are essential for repetitive firing (Miyamae et al., 2017), in G42-Kcns $3^{+/+}$(15 cells from 7 mice) and G42-Kcns $3^{\text {neo/neo }}$ (16 cells from 8 mice) animals. Except for a significantly smaller amplitude of the afterhyperpolarization in PVBCs from Kcns3-deficient mice (Fig. 5A), the membrane properties did not differ by Kcns3 genotype. The threshold current necessary to evoke spikes, or rheobase, was $\sim 50 \mathrm{pA}$ higher in PVBCs from Kcsn3-deficient mice, however the rheobase showed high variability (Miyamae et al., 2017). Hence, individual PVBCs from either genotype displayed high or low rheobase and the difference in rheobase between groups was non-significant (Fig. 5B). In both G42-Kcns $3^{+/+}$and G42-Kcns $3^{\text {neo/neo }}$ mice, PVBCs displayed either short or long delay to fire the first action potential with rheobase stimulus, consistent with the presence of both continuous FS and delayed FS subtypes, as described previously (Goldberg et al., 2008). The delay to fire the first action potential is controlled by Kv1.1 channels (Goldberg et al., 2008) and was not changed in Kcns3deficient PV neurons (Fig. 5B).

To test whether Kcns3 deficiency affects repetitive firing, as in the simulations in the FS cell model, we elicited spike trains applying steps of depolarizing current in $10 \mathrm{pA}$ increments (Fig. 6). Most PVBCs from G42-Kcns $3^{+/+}$mice displayed repetitive firing with nearly constant ISIs (Fig. 6A), which is classical of FS neurons (Goldberg et al., 2008). In contrast, many PVBCs from G42-Kcns $3^{\text {neo/neo }}$ mice showed spike trains with strong stuttering (Fig. 6B) which was very similar to that observed in the FS cell model with reduced $\mathrm{g}_{\mathrm{Kv} 2}$ (Fig. 3B), and required relatively large stimulus currents to convert into continuous firing (Fig. $6 \mathrm{~B})$.

Raster plots and plots of the $\mathrm{CV}_{\text {ISI }}$ built from the spike trains showed marked differences between PVBCs with weak or strong stuttering (Fig. 7A,B). In weak stuttering PVBCs, the $\mathrm{CV}_{\text {ISI }}$ decreased sharply with stimulus currents near threshold (Fig. 7A). In contrast, in strong stuttering PVBCs the $\mathrm{CV}_{\text {ISI }}$ was high near threshold and decreased progressively with stimuli well above threshold (Fig. 7B). Most PVBCs from G42-Kcns $3^{+/+}$mice had weak stuttering (Fig. 7C, left). In contrast, most PVBCs from G42-Kcns $3^{\text {neo/neo }}$ mice showed strong stuttering (Fig. $7 \mathrm{C}$, right), and displayed significantly higher $\mathrm{CV}_{\mathrm{ISI}}$ across a range of stimulus intensities (Fig. 7D), as observed in the FS cell model with low $\mathrm{g}_{\mathrm{Kv} 2}$ (Fig. 3C,D). These alterations of repetitive firing in PVBCs are similar to the predictions from our simulations in the FS cell model with reduced Kv2 conductance.

In strong stuttering PVBCs the spike trains had a larger proportion of long ISIs (Fig. $6 \mathrm{~B})$, suggesting that stuttering depresses PVBC spike output. To assess whether stuttering 
significantly affects PVBC spike output, we built frequency-current (f-I) plots. The individual (Fig. 7E) and average (Fig. 7F) f-I plots showed lower spike output in G42Kcns $3^{\text {neo/neo }}$ mice with currents $220 \mathrm{pA}$ and $\leq 70 \mathrm{pA}$ above threshold, a stimulus range that elicited spiking in the gamma frequency band $(30-80 \mathrm{~Hz})$.

Given that in other types of neurons, Kv2.1 currents control spike frequency adaptation (Guan et al., 2013; Romer et al., 2019), one possibility is that Kv2.1-Kv9.3 channels contribute to the low spike frequency adaptation typical of FS cells (Hu et al., 2014). To test this idea, in spike trains elicited by current steps in the experiments depicted in Fig. 7, we quantified spike frequency adaptation computing the ISI $_{\text {ratio, }}$ or ratio between the last and first ISI, expected to show values near 1 if spike frequency adaptation is low. As shown in Table 2, at the stimulus range in which Kcns3 deficiency increased stuttering

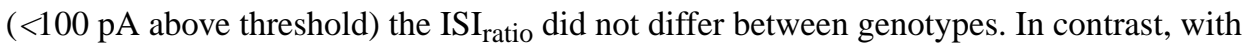
strong stimuli ( $>100 \mathrm{pA}$ above threshold), that elicited firing at frequency $>120 \mathrm{~Hz}$, PVBCs from G42-Kcns $3^{+/+}$mice showed an $\mathrm{ISI}_{\text {ratio }} \sim 1$, whereas PVBCs from G42-Kcns3 $3^{\text {neo/neo }}$ mice displayed $\sim 25-30 \%$ significantly higher ISI $_{\text {ratio }}$ (Table 2 ). These data suggest that Kv2.1- Kv9.3 channels regulate spike frequency adaptation exclusively in the stronger stimulus range where the $\mathrm{CV}_{\text {ISI }}$ was not significantly affected. Conversely, the ISI ratio $_{\text {as }}$ not affected by Kcns 3 deficiency within the lower stimulus range where the $\mathrm{CV}_{\text {ISI }}$ was significantly altered. Hence, the effects of Kcns 3 deficiency on the $\mathrm{CV}_{\text {ISI }}$ and the ISI $\mathrm{I}_{\text {ratio }}$ appear to be mediated by different mechanisms. Moreover, since the changes in ISI ratio $_{\text {were }}$ observed only with very strong stimuli, it is likely that the effects on the $\mathrm{CV}_{\text {ISI }}$ have a greater impact on recruitment of PVBCs by natural stimuli.

In addition to the changes in spike frequency adaptation, we observed that the amplitude of action potentials decreased during high frequency spike trains elicited by strong currents above the range producing stuttering (Supplemental Fig. 3A). Moreover, the magnitude of this decrease in action potential amplitude was significantly greater in PVBCs from G42-Kcns $3^{\text {neo/neo }}$ mice (Supplemental Fig. 3B). The action potential amplitude depends on the availability of voltage-gated $\mathrm{Na}^{+}$channels, which may decrease during spike trains due to $\mathrm{Na}^{+}$channel inactivation associated with repetitive firing. Hence, these data support the idea that the effects of Kcns3 deficiency are mediated, at least in part, by an increased $\mathrm{Na}^{+}$ channel inactivation due to a loss of Kv2 currents, which normally facilitate the recovery of $\mathrm{Na}^{+}$channels from inactivation.

An important question regarding the effects of Kcns 3 deficiency is to what extent the changes observed in our current clamp experiments are associated with a significant decrease of voltage-gated $\mathrm{K}^{+}$currents in PVBCs from Kcns3-deficient mice. Addressing this question requires voltage clamp recordings which however, if performed in neurons in brain slices, are predicted to involve significant voltage clamp errors that greatly distort the recorded Kv currents (Bar-Yehuda and Korngreen, 2008). To assess whether clamp errors affect the quantitative analysis of $\mathrm{Kv}$ currents, we obtained voltage clamp recordings from PV neurons in brain slices from G42-Kcns $3^{+/+}$mice ( $n=10$ cells from 2 mice). Kv currents were isolated by the addition of tetrodotoxin $(1 \mu \mathrm{M})$ and $\mathrm{Cd}^{2+}(50 \mu \mathrm{M})$ to block voltagegated $\mathrm{Na}^{+}$and $\mathrm{Ca}^{2+}$ channels, respectively. As shown in Supplemental Fig. 4A, depolarizing pulses elicited substantial Kv currents, typically reaching peak amplitudes in the range 
of 3-10 nA. Whereas the size of the Kv currents is consistent with their importance for PVBC physiology, their large amplitude was likely associated with the significant voltage clamp errors that became evident during analysis of Kv current activation (Supplemental Fig. 4B). The activation curves displayed errors quite similar to, and possibly larger than, those described by Bar-Yehuda and Korngreen, 2008 (Bar- Yehuda and Korngreen, 2008). Specifically, the activation curves did not show a plateau for depolarizing commands of +40 and $+60 \mathrm{mV}$, in marked contrast with the known voltage dependence of Kv2.1-Kv9.3 or Kv2.1 conductance studied in the absence of space clamps errors (Kerschensteiner and Stocker, 1999; Patel et al., 1997). Hence, the absence of plateau in the Kv conductance analysis precluded us from comparing the $\mathrm{Kv}$ currents between genotypes, because testing the effects of Kcns3 deficiency strictly requires assessing the plateau or saturation portion of the activation curve of the Kv conductance (Bar-Yehuda and Korngreen, 2008).

\subsection{Kcns3 deficiency disrupts PV neuron spike output during UP states}

Our experiments and simulations using standard steps of depolarizing current showed that Kcns3 deficiency alters the classical FS phenotype of PV neurons, producing irregular firing, or stuttering, and decreasing spike output in the gamma frequency band. Current steps, however, may not reveal the effects of Kcns3 deficiency on PV neuron activity driven by more natural stimuli. Thus, next we assessed the effects of Kcns3 deficiency on the transformation of excitatory input into spike output, studying spike trains elicited by injecting excitatory current with the shape of synaptic input observed during cortical UP states (Fig. 8A). UP states are episodes of increased recurrent network activity that involve both pyramidal cells and PV neurons (Fanselow and Connors, 2010; Puig et al., 2008; Zucca et al., 2017). Moreover, during UP states, single neurons are usually depolarized near spike threshold, and fire a few action potentials (Hasenstaub et al., 2005; Shu et al., 2003). To investigate the effects of Kcns3 deficiency on PVBC spike output during UP states, we first induced UP states in PFC slices from $\mathrm{Kcns}^{+/+}$mice using a previously described protocol (Sanchez-Vives and McCormick, 2000). Synaptic input observed in single neurons during UP states was recorded, stored digitally and used for stimulation with current injection (Fig. 8), comparing the response of PVBCs from $\mathrm{Kcns}^{+/+}$versus $K c n s 3^{\text {neo/neo }}$ mice. We injected the UP state-like currents increasing, in $10 \mathrm{pA}$ increments, the mean current injected during the first UP state $\left(\mathrm{UP}_{1}\right)$ until eliciting spikes, defining stimulus strength 1 , and up to 4 stimulus strengths.

During UP states, PVBC spikes were elicited at the peaks of injected current (Fig. 8B) as expected with injections of variable current (Mainen and Sejnowski, 1995). We assessed the response of PVBCs to the UP state-like stimulus computing the spike probability, $\mathrm{p}$ (spike), in $2 \mathrm{~ms}$ windows throughout the spike trains elicited by ten identical repeats of each stimulus pattern and strength (Fig. 8C). The curves of $\mathrm{p}$ (spike) showed peaks time-locked to the peaks of injected current (Fig. 8B), while the height of the peaks of $\mathrm{p}$ (spike) increased with stimulus strength (Fig. 8C), reflecting the increased likelihood of recruiting PVBCs as the input strength increased.

Consistent with previous reports that UP states are associated with gamma frequency (30$80 \mathrm{~Hz}$ ) network activity (Hasenstaub et al., 2005; Shu et al., 2003), the synaptic activity 
recorded during UP states showed successive peaks at gamma frequency (Fig. 8A,B). When injected into PVBCs, the UP state-like input produced brief bursts of spike output at gamma frequency (Fig. 8B). Therefore, the injection of UP state-like currents allowed us to test whether Kcns3 deficiency affects the response to natural inputs that elicit PVBC output in the gamma frequency band.

To compare between genotypes the spike output during UP states, we obtained a curve of average $\mathrm{p}$ (spike) by averaging across neurons the curves obtained for each neuron at a given stimulus strength (Fig. 9A), in the PVBCs from G42-Kcns $3^{+/+}(n=25$ cells from 15 mice), and from G42-Kcns $3^{\text {neo/neo }}$ mice ( $\mathrm{n}=25$ cells from 14 mice). The curves of average $\mathrm{p}$ (spike) showed peaks with identical timing in PVBCs from G42-Kcns $3^{+/+}$and G42-Kcns $3^{\text {neo/neo }}$ mice, as the PVBCs from either genotype responded to the same peaks of input current (Fig. 9A). The peaks of average p(spike) with identical timing share, across genotypes, the previous history of input current and hence were paired for comparison between genotypes. We found that in most pairs of peaks of average $\mathrm{p}$ (spike), the PVBCs from Kcns3-deficient mice had lower peak height (Fig. 9A,B). Pair-wise comparisons (Fig. 9B) showed that the reduced height of the peaks of average $\mathrm{p}$ (spike) became significant as the stimulus strength increased (Fig. 9C). These data suggest that Kcns3 deficiency reduces the probability of PVBC recruitment by UP state-like stimulus patterns.

During natural network activity, the patterns of input associated with discrete UP states are likely to be unique to each UP state. Hence, we wondered whether the changes in average $\mathrm{p}$ (spike) revealed using 10 identical repeats of each UP state-like stimulus pattern may predict the changes in the probability of recruiting PVBCs with a single application of a stimulus pattern. If so, then Kcns3 deficiency should reduce the number of PVBCs recruited by a single repeat of each UP state. We tested this possibility assessing the number of PVBCs recruited by the first of the ten repeats of each UP state-like stimulus. We found peaks in the number of PVBCs recruited matched in timing the peaks of average $p$ (spike) (Fig. 9D). The peaks in the number of recruited PVBCs were lower in Kcns3-deficient mice (Fig. 9E), and the reduction in the number of PVBCs recruited became significant with increasing stimulus strength (Fig. 9F). These data thus suggest that by reducing $\mathrm{p}$ (spike), Kcns3 3 deficiency reduces the fraction of PVBCs recruited when the local excitatory network generates UP state activity particularly, but not exclusively, in the gamma frequency band.

\subsection{Kcns3 deficiency does not affect EPSPs in PV basket cells}

The experiments testing the response to stimulus patterns mimicking synaptic input during UP states showed that Kcns 3 deficiency reduces the probability of recruiting the PVBCs. Importantly, PV neuron physiology is tuned for fast input-output transformation (Hu et al., 2014; Jonas et al., 2004), and the synaptic events at their excitatory inputs display rapid decay kinetics (Angulo et al., 1999; Geiger et al., 1997; Rotaru et al., 2011). Previously, we hypothesized that, in PV neurons, subthreshold EPSPs activate the Kv2.1-Kv9.3 channels eliciting a $\mathrm{K}^{+}$current that accelerates the EPSP decay, and hence that Kcns 3 deficiency prolongs the EPSP decay, abnormally enhancing EPSP summation (Georgiev et al., 2012; Georgiev et al., 2014). 
If in PVBCs from Kcns3-deficient mice the EPSP decay is prolonged, then the spike output of PVBCs during UP states may be affected. For example, abnormal summation of EPSPs could prolong the time spent by the PVBC membrane potential in a depolarized state below action potential threshold, which could increase the inactivation of $\mathrm{Na}^{+}$channels. If so, recruitment of PV neurons during UP states should be reduced. Alternatively, prolonged EPSP decay with Kcns3 deficiency may enhance EPSP summation producing an excess of spikes with abnormal timing during UP states, opposing the effect observed in this study (Fig. 9).

To test our hypothesis that Kcns3 deficiency prolongs the EPSP decay (Georgiev et al., 2012; Georgiev et al., 2014), we recorded spontaneous EPSPs (sEPSPs) from PVBCs in layers 2-5 in slices prepared from the PFC of G42- $\mathrm{Kcns}^{+/+}$and G42-Kcns $3^{\text {neo/neo }}$ mice (Fig. 10). sEPSPs recorded from PV neurons at the resting membrane potential are largely AMPA receptor-mediated, and display small NMDA receptor-mediated contribution relative to sEPSPs similarly recorded from pyramidal cells (Rotaru et al., 2011). PVBCs showed frequent sEPSPs with a wide range of peak amplitudes and fast decay (Fig. 10A). However, contrary to our predictions, the decay time course of the average sEPSP did not differ by genotype (Fig. 10B). The absence of effect of Kcns 3 deficiency on the sEPSP decay phase was not due to absence of regulation of the sEPSP decay by Kv channels, because bath application of $10 \mathrm{mM}$ tetraethylammonium (TEA), a non-selective Kv channel blocker, prolonged the sEPSP decay time in PVBCs from G42-Kcns $3^{+/+}$mice (control: $6.8 \pm 2.4 \mathrm{~ms}$, TEA: $8.5 \pm 3.2 \mathrm{~ms}, n=8$ cells from 2 mice, $p=0.0265$, paired samples $t$-test), as reported for hippocampal PVBCs (Hu et al., 2010).

It is possible that only the sEPSPs with largest amplitudes, which are a small fraction of all sEPSPs (Fig. 10A), produce enough depolarization to activate the Kv2.1-Kv9.3 channels and accelerate the sEPSP decay time course. If so, the large sEPSPs should display longer decay phase in PVBCs from $\mathrm{Kcns}^{\text {neo/neo }}$ versus $\mathrm{Kcns}^{3^{+/+}}$mice. To test this prediction, we selected the sEPSPs with peak amplitude $>1 \mathrm{mV}$ (sEPSPs $>1 \mathrm{mV}$ ). The sEPSPs $>1 \mathrm{mV}$ had peak amplitude $\sim 3$ times greater than the average $\operatorname{sEPSP}\left(\mathrm{G} 42-k c n s 3^{+/+}: 1.5 \pm 0.3 \mathrm{mV}\right.$ versus $0.6 \pm 0.2 \mathrm{mV}, n=11$ cells, $p=0.000081$, Mann Whitney's test; G42-kcns $3^{\text {neo }} /$ neo: 1.9 $\pm 1.1 \mathrm{mV}$ versus $0.6 \pm 0.1 \mathrm{mV}, \mathrm{n}=11$ cells; $p=0.0000028$, Mann Whitney's test). However, the decay time constant of the sEPSPs $>1 \mathrm{mV}$ did not differ between genotypes (Fig. 10C). These data show that EPSP duration in PVBCs is not affected by Kcns3 deficiency, suggesting that PVBC firing during UP states is not affected by abnormal EPSP summation.

\section{Discussion}

We assessed the role of Kv9.3 subunits in PV neuron electrophysiology using a line of Kcns3-deficient mice. Together with a previous study of Kv9.1 subunits in sensory neurons (Tsantoulas et al., 2012), the present report demonstrates that decreased expression of $\mathrm{K}^{+}$ channel genes encoding subunits of the silent Kv subfamily, significantly alters neuronal physiology. Kv9.3 subunits are thought to amplify Kv2.1 currents, which regulate repetitive firing in other types of neurons. Hence, we hypothesized that lower Kv9.3 subunit levels may affect repetitive firing in PV neurons in a manner consistent with loss of Kv2 current. We first tested the effects of decreasing Kv2.1 on repetitive firing in a computational model 
of PV FS cells. Our simulations showed that reducing Kv2.1 produces irregular ISIs, or stuttering, via an increase of $\mathrm{Na}^{+}$channel inactivation. Consistent with our simulations, PVBCs from Kcns3-deficient mice exhibited strong stuttering, indicating that Kcns3 deficiency critically affects the classical FS phenotype of PVBCs. Moreover, consistent with an effect through increased $\mathrm{Na}^{+}$channel inactivation, PVBCs from Kcns3-deficient mice showed enhanced attenuation of the action potential amplitude during high frequency spike trains. Disruption of the FS phenotype was accompanied by impaired recruitment of PVBCs by natural patterns of input such as those observed during cortical UP states, which normally recruit PV neuron firing at gamma frequency band. Our experiments with Kcsn3-deficient mice therefore suggest that $K C N S 3$ deficiency in schizophrenia might affect cortical circuit function by disrupting the firing properties of PVBCs.

\subsection{Gene expression changes in Kcns $3^{\text {neo/neo }}$ mice}

The insertion of the trapping cassette into the intron directly upstream of the protein coding exon of the Kcns3 gene (Fig. 1A), resulted in a partial $45 \%$ reduction of Kcns 3 mRNA in cortical tissue from $K c n s 3^{\text {neo/ neo }}$ mice, as revealed by qPCR using primers that amplified a protein- coding sequence of the mRNA (Fig. 1). Such partial effects of trapping cassettes have been previously reported for multiple genes (Serafini et al., 1996; Voss et al., 1998; Yeo et al., 1997) and attributed to the splicing of pre-mRNAs around a trapping cassette or to transcription driven by an alternative promoter. Consistent with the qPCR results, single-cell ISH analysis showed a $50 \%$ decrease of Kcns 3 mRNA expression in cortical PV neurons of $K c n s 3^{\text {neo/neo }}$ mice (Fig. 2). The distribution of Kcns3 mRNA expression per single PV cell partially overlapped between $K c n s 3^{+/+}$and $K c n s 3^{\text {neo/neo }}$ mice, showing that some PV neurons in $K c n s 3^{\text {neo/neo }}$ mice had Kcns 3 mRNA levels typical of $K c n s 3^{+/+}$mice and thus may display an intact physiological phenotype. Consistent with this interpretation, some PV neurons from Kcns $3^{\text {neo/neo }}$ mice had unaltered electrophysiology (Fig. 7).

Kv9.3 subunits form heteromeric Kv2.1-Kv9.3 channels. Because expression of Kcnb1, the gene encoding Kv2.1, was not altered in PV neurons from Kcns $3^{\text {neo/neo }}$ mice (Fig. 2), the observed alterations of PVBC physiology in $K c n s 3^{\text {neo/neo }}$ mice are likely specific to lower levels of Kv9.3 subunits.

\subsection{Kens3 deficiency disrupts the input-output transformation properties of PV neurons}

To assess how Kcns3 deficiency affects the FS phenotype of PV neurons, in a computational FS cell model we decreased the Kv2.1 conductance, one of the effects expected from the loss of Kv9.3-mediated modulation of the Kv2.1 current. We found that in the FS cell model with reduced Kv2.1 conductance, spike trains displayed strong stuttering (Fig. 3). Our simulations also suggest that one of the mechanisms by which reduced Kv2.1 conductance may increase stuttering involves greater inactivation of the $\mathrm{Na}^{+}$channels, possibly caused by a smaller afterhyperpolarization amplitude (Fig. 3, Supplemental Fig. 1). Our simulation data therefore lead us to predict that due to lower levels of $\mathrm{Kv} 9.3$ subunits, PVBCs from G42-Kcns $3^{\text {neo/neo }}$ mice should display strong stuttering. In experiments with G42-Kcns $3^{\text {neo/neo }}$ mice, PVBCs had strong stuttering (Figs. 6 and 7), in a manner consistent with the predictions of our simulations in the FS cell model. 
Our experiments produced results consistent with the predictions from the computational model, which considered the effects of Kv9.3 subunits on the activation of the Kv2.1 conductance but did not assess the effects of Kv9.3 on Kv2.1 inactivation. Importantly, Kv9.3 subunits have complex effects on Kv2.1 inactivation, producing a hyperpolarizing shift in its voltage dependence (Kerschensteiner and Stocker, 1999; Patel et al., 1997), while decreasing and increasing inactivation from the open or closed states, respectively (Kerschensteiner et al., 2003). These opposing effects on Kv2.1 channels could significantly influence the response of the PV neuron membrane potential during series of synaptic depolarizations such as those produced during UP states. For instance, after periods of lower synaptic activity the Kv2.1 current might be reduced due to closed state inactivation but would be amplified over the course of intense synaptic activity. If so, then the loss of Kv9.3 might reduce the dynamic range of Kv2.1 currents across different conditions of synaptic input.

State-dependent inactivation of transient A-type Kv currents is thought to significantly impact membrane excitability during the response to series of synaptic depolarizations (Johnston et al., 2000). However, Kv2.1 and Kv2.1-Kv9.3 currents display significantly slower inactivation time constants than A-type Kv currents (Rasmussen and Trimmer, 2018). Hence, future modeling studies considering the effects of Kv9.3 subunits on Kv2.1 inactivation are necessary to fully assess the effects of Kcns 3 deficiency and to obtain additional predictions regarding changes in PV neuron electrophysiology.

The experiments injecting current steps also showed that increased stuttering is associated with reduced spike output in the gamma frequency band (Fig. 7). Moreover, Kcns3 deficiency also decreased PVBC spike output produced by stimulation with UP state-like stimulus currents (Fig. 9). UP states are episodes of increased network activity that engage pyramidal cells and PV neurons (Fanselow and Connors, 2010; Puig et al., 2008; Zucca et al., 2017), and produce rhythmic network activity in the gamma band (Hasenstaub et al., 2005; Shu et al., 2003). We found that PVBCs recruited by the UP state-like stimulus fired brief bursts of spikes at gamma frequency (Fig. 8), and that the probability of PVBC firing during these gamma bursts was reduced in G42-Kcns $3^{n e o / n e o}$ mice (Fig. 9). Our data therefore suggest that Kv9.3 channels critically shape PVBC electrophysiology when tested using either standard (current steps) or more natural (UP state-like) stimuli. Moreover, our data indicate that Kcns3 deficiency disrupts the capacity of a network of PVBCs to fire during UP state episodes that normally produce bursts of gamma frequency firing.

The effects of Kcns 3 deficiency on the response to UP states could be mechanistically related to the stuttering effects observed in the response to current steps. For instance, it is possible that relatively prolonged depolarization of the PVBCs membrane potential below action potential threshold throughout the UP states produces inactivation of $\mathrm{Na}^{+}$channels that interacts with the effect of Kcns 3 deficiency to reduce UP state- related PVBC firing.

Although the conditions of the UP state-like current injection experiments do not involve actual changes in network activity, the injection of UP state-like current likely mimics the pattern of input arriving onto single neurons during the gamma synchrony episodes typically associated with the UP states. It is unclear, however, whether injection of UP state-like 
current directly into the soma adequately simulates the effects of inputs naturally arriving onto dendrites. However, while PV neuron dendrites possess active properties, ion channels in PV cell dendrites mostly support action potential back propagation, and do not seem to generate local dendritic potentials that could mediate dendritic integration of synaptic inputs prior to their propagation to the action potential initiation site near the soma (Hu et al., 2010).

\subsection{Kcns3 deficiency does not affect synaptic input onto PV neurons}

We proposed previously that Kv2.1-Kv9.3 channels are more effectively activated by subthreshold EPSPs than homomeric Kv2.1 channels (Georgiev et al., 2012; Georgiev et al., 2014), and accelerate the EPSP decay. However, we found that sEPSPs, including the sEPSPs $>1 \mathrm{mV}$, were unaltered in PVBCs from Kcns3-deficient mice (Fig. 10). One possibility is that due to their voltage dependence of activation (Bocksteins, 2016), Kv2.1Kv9.3 channels are minimally activated by EPSPs. However, although small when recorded at the PV neuron soma, in dendrites EPSPs are up to $~ 20$ times larger, prior to their severe attenuation during dendrite-to-soma propagation (Hu et al., 2010; Norenberg et al., 2010). Interestingly, qualitative analysis of the subcellular distribution of Kv2.1 subunits in hippocampal PV neurons suggests that Kv2.1 channels may be present in dendrites (Du et al., 1998), where subthreshold EPSPs have the largest amplitude. However, the subcellular localization of Kv9.3 subunits has not been characterized in cortical PV neurons. Thus, one possibility is that the EPSP shape is not changed in Kcns3-deficient PV neurons because Kv9.3 subunits are absent in dendrites, and that, due to their small amplitude at the soma, sEPSPs fail to gate a significant fraction of Kv2.1-Kv9.3 channels. Alternatively, if Kv2.1-Kv9.3 channels are indeed located in PV neuron dendrites, the absence of Kv2.1Kv9.3 channel-mediated regulation of EPSPs would suggest that depolarizations larger than somatic or dendritic EPSPs, such as those produced by action potentials, are necessary to activate Kv2.1- Kv9.3 channels. Future studies should address whether Kv2.1-Kv9.3 channels are localized in PV neuron dendrites and if so, whether large compound EPSPs produced by simultaneous stimulation of multiple synapses reveal effects of Kv9.3 loss indicative of Kv2.1-Kv9.3 channel activation by the compound EPSPs that is not produced by spontaneous EPSPs. At least in hippocampus, PV neuron dendrites seem to lack local electrogenesis mechanisms, suggesting that a major role of dendritic Kv channels is regulating action potential back propagation (Hu et al., 2010). The effects of Kcns3 deficiency reported here are thus likely the result of changes in $\mathrm{Kv}$ channels near the perisomatic action potential initiation site. However, we cannot rule out that complex interactions between dendritic and somatic $\mathrm{Kv}$ activation mediate the effects, a possibility that remains to be addressed in future studies.

\subsection{Implications for cortical circuit dysfunction in schizophrenia}

PV neurons from mouse and human neocortex express highly conserved varieties of voltagegated channel genes, including Kv genes (Enwright et al., 2018; Krienen et al., 2020; Okaty et al., 2009). These similarities are consistent with data showing that PV neurons from human neocortex display FS properties, as observed experimentally (Stedehouder et al., 2019; Stedehouder et al., 2017; Szegedi et al., 2017; Szegedi et al., 2020; Wang et al., 2016). Given that electrophysiology and gene expression are conserved, it is likely that 
Kcns3 deficiency produces qualitatively similar changes in the physiological properties of PV neurons from both mouse and human neocortex.

Previous postmortem studies reported that $K C N S 3$ mRNA levels were lower by $30-40 \%$ in PV neurons from the PFC of schizophrenia subjects compared with unaffected comparison subjects (Enwright et al., 2018; Georgiev et al., 2014). Therefore, our Kcns3-deficient mice with 50\% reduction in Kcns3 mRNA levels in PV neurons appear to be an appropriate animal model to address the effects of the partial deficit of $K C N S 3$ expression in PV neurons in schizophrenia. Importantly, whereas $K c n b 1$ mRNA levels were unaltered in Kcns3-deficient mice, $K C N B 1$ mRNA levels were lower in DLPFC PV neurons in schizophrenia in parallel with KCNS3 mRNA levels (Georgiev et al., 2014), suggesting a greater reduction of Kv2.1 current in schizophrenia. Hence, the alterations of PV neuron physiology due to deficient $K C N S 3$ expression might be greater in schizophrenia than in our line of Kcns3-deficient mice.

The mechanisms leading to lower $K C N S 3$ expression in schizophrenia are currently unknown. Remarkably, the expression of $\mathrm{Kv}$ channel genes, including Kcns3, is activitydependent (Dehorter et al., 2015; Lee et al., 2015), suggesting that downregulation of $K C N S 3$ expression in schizophrenia is secondary to the lower levels of cortical network activity (Arion et al., 2015; Lewis et al., 2012). Our experiments in Kcns3-deficient mice suggest that $K C N S 3$ downregulation in schizophrenia, while possibly triggered by reduced network activity, is not a homeostatic adaptation to restore PV cell activity. Instead, Kcns3 downregulation seems to produce a deficit in PV cell recruitment.

In schizophrenia, the alterations in PV neurons due to $K C N S 3$ deficiency might interact with a decrease in excitatory input (Chung et al., 2016), additionally impairing PV neuron recruitment. Impaired PVBC recruitment due to lower number of excitatory synapses may be independent of the firing rate of presynaptic excitatory neurons. However, our experiments with Kcns3-deficient mice suggest that PVBC recruitment may be affected particularly, but not exclusively, during rhythmic excitatory synaptic input such as that observed during gamma band oscillations (Atallah and Scanziani, 2009; Mann et al., 2005; Oren et al., 2006). Thus, KCNS3 deficiency, together with other alterations in PV neurons (Dienel and Lewis, 2019), might contribute to the decrease in gamma oscillation power observed in schizophrenia under task conditions, such as those engaging working memory (Uhlhaas and Singer, 2015), that normally induce gamma band activity (Miller et al., 2018).

As the expression of PV is regulated by neuronal activity (Carder et al., 1996; Cohen et al., 2016), we assessed whether the changes in PVBC properties with Kcns3 deficiency could decrease Pvalb mRNA levels in a manner similar to that observed in PV neurons in schizophrenia. However, we did not detect a change in Pvalb mRNA levels in Kcns3deficient mice, suggesting that lower KCNS3 mRNA levels in PV neurons might not be sufficient to induce deficits in PV levels in schizophrenia. Additional studies are needed to further address similarities between the phenotype of Kcns3-deficient mice and the alterations observed in schizophrenia. For example, experiments studying gamma oscillations induced in vitro or assessed in vivo, and behavioral tests assessing cognitive performance in mice, may help linking the effects of Kcns3 deficiency reported here to 
the alterations of PV neurons, gamma oscillations and cognition observed in subjects with schizophrenia.

\subsection{Limitations of this study}

While providing the first demonstration of an important role of $K c n s 3$, the gene encoding Kv9.3 subunits, in the FS phenotype of PV neurons, our study had limitations that should be addressed in future studies to clarify the mechanisms by which KCNS3 deficiency may affect FS properties in schizophrenia. First, the magnitude of decrease in Kv9.3 subunit protein levels in PV neurons from Kcns3-deficient mice needs to be determined, given that changes in mRNA levels may not always reflect changes in the corresponding protein. Second, it needs to be demonstrated that Kv2.1 and Kv9.3 subunits are co-assembled in PV neurons. Third, the changes in Kv2 currents in PV neurons from Kcns3- deficient versus wild type mice should be assessed, to test if Kv2 current density, its biophysical properties, or both, are affected. Given that whole-cell voltage clamp recordings from neurons in slices cannot properly quantify $\mathrm{Kv}$ currents, future studies should employ techniques such as voltage-clamp in nucleated patches which are technically more difficult but are not limited by voltage clamp errors. Finally, whereas the lower Kcns3 mRNA levels in our mouse model are a consequence of manipulating the gene, there are no allelic variants of $K C N S 3$ associated with schizophrenia and known to decrease $K C N S 3$ expression. Instead, it is likely that $K C N S 3$ downregulation reflects upstream mechanisms that also affect the expression of other voltage-gated ion channel genes in PV neurons, including $\mathrm{KCNC1}$ (Yanagi et al., 2014) and KCNB1 (Enwright et al., 2018; Georgiev et al., 2014). Therefore, it is necessary to test the effect of KCNS3 deficiency using models that better recapitulate altered expression of ion channel molecules in PV neurons in schizophrenia.

\section{Supplementary Material}

Refer to Web version on PubMed Central for supplementary material.

\section{Acknowledgments}

We thank Junko Konishi for the maintenance of mouse colonies, Olga Krimer for assistance with brain slice preparation, tissue staining and digital reconstructions of neuron morphology, and Yelena Gulchina for electrophysiological experiments during early stages of this project.

This work was supported by the Japan Society for the Promotion of Science Grants-in-Aid 25293247 and 15H01280 to TH, and National Institutes of Health Grant Nos. MH51234 (to DAL) and P50MH103204 (to DAL, GG-B).

DAL currently receives investigator-initiated research support from Merck and Pfizer and serves as a consultant to Astellas. The other authors report no biomedical financial interests or potential conflicts of interest.

\section{References}

Angulo MC, et al. , 1999. Postsynaptic glutamate receptors and integrative properties of fast-spiking interneurons in the rat neocortex. J. Neurophysiol 82, 1295-1302. [PubMed: 10482748]

Antonoudiou P, et al. , 2020. Parvalbumin and Somatostatin interneurons contribute to the generation of hippocampal gamma oscillations. J. Neurosci 40, 7668-7687. [PubMed: 32859716]

Arion D, et al. , 2015. Distinctive transcriptome alterations of prefrontal pyramidal neurons in schizophrenia and schizoaffective disorder. Mol. Psychiatry 20, 1397-1405. [PubMed: 25560755] 
Atallah BV, Scanziani M, 2009. Instantaneous modulation of gamma oscillation frequency by balancing excitation with inhibition. Neuron. 62, 566-577. [PubMed: 19477157]

Barch DM, Ceaser A, 2012. Cognition in schizophrenia: core psychological and neural mechanisms. Trends Cogn. Sci 16, 27-34. [PubMed: 22169777]

Bar-Yehuda D, Korngreen A, 2008. Space-clamp problems when voltage clamping neurons expressing voltage-gated conductances. J. Neurophysiol 99, 1127-1136. [PubMed: 18184885]

Bocksteins E, 2016. Kv5, Kv6, Kv8, and Kv9 subunits: no simple silent bystanders. J Gen Physiol. 147, 105-125. [PubMed: 26755771]

Buchanan KA, et al. , 2012. Target-specific expression of presynaptic NMDA receptors in neocortical microcircuits. Neuron. 75, 451-466. [PubMed: 22884329]

Buzsaki G, Wang XJ, 2012. Mechanisms of gamma oscillations. Annu. Rev. Neurosci 35, 203-225. [PubMed: 22443509]

Carder RK, et al. , 1996. Regulation of calcium-binding protein immunoreactivity in GABA neurons of macaque primary visual cortex. Cereb. Cortex 6, 271-287. [PubMed: 8670656]

Chattopadhyaya B, et al. , 2004. Experience and activity-dependent maturation of perisomatic GABAergic innervation in primary visual cortex during a postnatal critical period. J. Neurosci 24, 9598-9611. [PubMed: 15509747]

Chen G, et al. , 2017. Distinct inhibitory circuits orchestrate cortical beta and gamma band oscillations. Neuron 96 (1403-1418.e6). [PubMed: 29268099]

Chung DW, et al. , 2016. Pathological basis for deficient excitatory drive to cortical Parvalbumin interneurons in schizophrenia. Am. J. Psychiatry 173, 1131-1139. [PubMed: 27444795]

Cohen SM, et al. , 2016. Excitation-transcription coupling in Parvalbumin-positive interneurons employs a novel CaM kinase-dependent pathway distinct from excitatory neurons. Neuron. 90, 292-307. [PubMed: 27041500]

Dehorter N, et al. , 2015. Tuning of fast-spiking interneuron properties by an activity- dependent transcriptional switch. Science. 349, 1216-1220. [PubMed: 26359400]

Descalzo VF, et al. , 2005. Slow adaptation in fast-spiking neurons of visual cortex. J. Neurophysiol 93, 1111-1118. [PubMed: 15385594]

Dienel SJ, Lewis DA, 2019. Alterations in cortical interneurons and cognitive function in schizophrenia. Neurobiol. Dis 131, 104208.

Donato F, et al. , 2013. Parvalbumin-expressing basket-cell network plasticity induced by experience regulates adult learning. Nature. 504, 272-276. [PubMed: 24336286]

Du J, et al. , 1996. Developmental expression and functional characterization of the potassium-channel subunit Kv3.1b in parvalbumin-containing interneurons of the rat hippocampus. J. Neurosci 16, 506-518. [PubMed: 8551335]

Du J, et al. , 1998. The $\mathrm{K}+$ channel, Kv2.1, is apposed to astrocytic processes and is associated with inhibitory postsynaptic membranes in hippocampal and cortical principal neurons and inhibitory interneurons. Neuroscience. 84, 37-48. [PubMed: 9522360]

Enwright JF, et al. , 2018. Transcriptome alterations of prefrontal cortical parvalbumin neurons in schizophrenia. Mol. Psychiatry 23, 1606-1613. [PubMed: 29112193]

Erisir A, et al. , 1999. Function of specific $\mathrm{K}(+)$ channels in sustained high-frequency firing of fast-spiking neocortical interneurons. J. Neurophysiol 82, 2476-2489. [PubMed: 10561420]

Ermentrout B, Wechselberger M, 2009. Canards, clusters, and synchronization in a weakly coupled interneuron model. SIAM J. Appl. Dyn. Syst 8, 253-278.

Fanselow EE, Connors BW, 2010. The roles of somatostatin-expressing (GIN) and fast-spiking inhibitory interneurons in UP-DOWN states of mouse neocortex. J. Neurophysiol 104, 596-606. [PubMed: 20538767]

Fleidervish IA, et al. , 1996. Slow inactivation of $\mathrm{Na}+$ current and slow cumulative spike adaptation in mouse and Guinea-pig neocortical neurones in slices. J. Physiol 493, 83-97. [PubMed: 8735696]

Geiger JR, et al. , 1997. Submillisecond AMPA receptor-mediated signaling at a principal neuroninterneuron synapse. Neuron. 18, 1009-1023. [PubMed: 9208867]

Georgiev D, et al. , 2012. Selective expression of KCNS3 potassium channel alpha- subunit in parvalbumin-containing GABA neurons in the human prefrontal cortex. PLoS One 7, e43904. 
Georgiev D, et al. , 2014. Lower gene expression for KCNS3 potassium channel subunit in parvalbumin-containing neurons in the prefrontal cortex in schizophrenia. Am. J. Psychiatry 171, 62-71. [PubMed: 24170294]

Georgiev D, et al. , 2016. Cortical gene expression after a conditional knockout of $67 \mathrm{kDa}$ glutamic acid decarboxylase in Parvalbumin neurons. Schizophr. Bull 42, 992-1002. [PubMed: 26980143]

Goldberg EM, et al. , 2008. K+ channels at the axon initial segment dampen near-threshold excitability of neocortical fast-spiking GABAergic interneurons. Neuron. 58, 387-400. [PubMed: 18466749]

Golomb D, et al. , 2007. Mechanisms of firing patterns in fast-spiking cortical interneurons. PLoS Comput. Biol 3, e156. [PubMed: 17696606]

Gonzalez-Burgos G, et al. , 2015. Alterations in cortical network oscillations and Parvalbumin neurons in schizophrenia. Biol. Psychiatry 77, 1031-1040. [PubMed: 25863358]

Guan D, et al. , 2013. Kv2 channels regulate firing rate in pyramidal neurons from rat sensorimotor cortex. J. Physiol 591, 4807-4825. [PubMed: 23878373]

Hasenstaub A, et al. , 2005. Inhibitory postsynaptic potentials carry synchronized frequency information in active cortical networks. Neuron. 47, 423-435. [PubMed: 16055065]

Helm J, et al. , 2013. Subgroups of parvalbumin-expressing interneurons in layers $2 / 3$ of the visual cortex. J. Neurophysiol 109, 1600-1613. [PubMed: 23274311]

$\mathrm{Hu} \mathrm{H}$, et al. , 2010. Dendritic mechanisms underlying rapid synaptic activation of fast- spiking hippocampal interneurons. Science. 327, 52-58. [PubMed: 19965717]

$\mathrm{Hu} \mathrm{H}$, et al. , 2014. Interneurons. Fast-spiking, parvalbumin(+) GABAergic interneurons: from cellular design to microcircuit function. Science 345, 1255263.

Johnston D, et al. , 2000. Dendritic potassium channels in hippocampal pyramidal neurons. J. Physiol 525 (Pt 1), 75-81. [PubMed: 10811726]

Jonas P, et al. , 2004. Interneuron diversity series: fast in, fast out-temporal and spatial signal processing in hippocampal interneurons. Trends Neurosci. 27, 30-40. [PubMed: 14698608]

Kahn RS, Keefe RS, 2013. Schizophrenia is a cognitive illness: time for a change in focus. JAMA Psychiatry. 70, 1107-1112. [PubMed: 23925787]

Kawaguchi Y, Kubota Y, 1997. GABAergic cell subtypes and their synaptic connections in rat frontal cortex. Cereb. Cortex 7, 476-486. [PubMed: 9276173]

Kerschensteiner D, Stocker M, 1999. Heteromeric assembly of Kv2.1 with Kv9.3: effect on the state dependence of inactivation. Biophys. J 77, 248-257. [PubMed: 10388754]

Kerschensteiner D, et al. , 2003. Structural determinants of the regulation of the voltage-gated potassium channel Kv2.1 by the modulatory alpha-subunit Kv9.3. J. Biol. Chem 278, 18154 18161. [PubMed: 12642579]

Krienen FM, et al. , 2020. Innovations present in the primate interneuron repertoire. Nature. 586, 262-269. [PubMed: 32999462]

Lau D, et al. , 2000. Impaired fast-spiking, suppressed cortical inhibition, and increased susceptibility to seizures in mice lacking Kv3.2 K+ channel proteins. J. Neurosci 20, 9071-9085. [PubMed: 11124984]

Lee KY, et al. , 2015. N-methyl-D-aspartate receptors mediate activity-dependent down- regulation of potassium channel genes during the expression of homeostatic intrinsic plasticity. Mol Brain. 8, 4 . [PubMed: 25599691]

Lewis DA, et al. , 2012. Cortical parvalbumin interneurons and cognitive dysfunction in schizophrenia. Trends Neurosci. 35, 57-67. [PubMed: 22154068]

Mainen ZF, Sejnowski TJ, 1995. Reliability of spike timing in neocortical neurons. Science. 268, 1503-1506. [PubMed: 7770778]

Mann EO, et al. , 2005. Perisomatic feedback inhibition underlies cholinergically induced fast network oscillations in the rat hippocampus in vitro. Neuron. 45, 105-117. [PubMed: 15629706]

Markram H, et al. , 2004. Interneurons of the neocortical inhibitory system. Nat. Rev. Neurosci 5, 793-807. [PubMed: 15378039]

Martina M, Jonas P, 1997. Functional differences in Na+ channel gating between fast-spiking interneurones and principal neurones of rat hippocampus. J. Physiol 505 (Pt 3), 593-603. [PubMed: 9457638] 
Miller EK, et al. , 2018. Working memory 2.0. Neuron. 100, 463-475. [PubMed: 30359609]

Miyamae T, et al. , 2017. Distinct physiological maturation of parvalbumin-positive neuron subtypes in mouse prefrontal cortex. J. Neurosci 37, 4883-4902. [PubMed: 28408413]

Norenberg A, et al. , 2010. Distinct nonuniform cable properties optimize rapid and efficient activation of fast-spiking GABAergic interneurons. Proc. Natl. Acad. Sci. U. S. A 107, 894-899. [PubMed: 20080772]

Okaty BW, et al. , 2009. Transcriptional and electrophysiological maturation of neocortical fastspiking GABAergic interneurons. J. Neurosci 29, 7040-7052. [PubMed: 19474331]

Oren I, et al. , 2006. Synaptic currents in anatomically identified CA3 neurons during hippocampal gamma oscillations in vitro. J. Neurosci 26, 9923-9934. [PubMed: 17005856]

Patel AJ, et al. , 1997. Kv2.1/Kv9.3, a novel ATP-dependent delayed-rectifier K+ channel in oxygensensitive pulmonary artery myocytes. EMBO J. 16, 6615-6625. [PubMed: 9362476]

Paul A, et al. , 2017. Transcriptional architecture of synaptic communication delineates GABAergic neuron identity. Cell 171 (522-539.e20). [PubMed: 28942923]

Povysheva NV, et al. , 2008. Parvalbumin-positive basket interneurons in monkey and rat prefrontal cortex. J. Neurophysiol 100, 2348-2360. [PubMed: 18632882]

Puig MV, et al. , 2008. Cell type-specific control of neuronal responsiveness by gamma-band oscillatory inhibition. Proc. Natl. Acad. Sci. U. S. A 105, 8428-8433. [PubMed: 18550841]

Rasmussen HB, Trimmer JS, 2018. The voltage-dependent K+ channel family. In: Bhattacharjee A (Ed.), The Oxford Handbook of Neuronal Ion Channels. 10.1093/oxfordhb/9780190669164.013.1. https://www.oxfordhandbooks.com/.

Romer SH, et al. , 2019. A molecular rheostat: Kv2.1 currents maintain or suppress repetitive firing in motoneurons. J. Physiol 597, 3769-3786. [PubMed: 31145471]

Rotaru DC, et al. , 2011. Glutamate receptor subtypes mediating synaptic activation of prefrontal cortex neurons: relevance for schizophrenia. J. Neurosci 31, 142-156. [PubMed: 21209199]

Rudy B, McBain CJ, 2001. Kv3 channels: voltage-gated K+ channels designed for high-frequency repetitive firing. Trends Neurosci. 24, 517-526. [PubMed: 11506885]

Sanchez-Vives MV, McCormick DA, 2000. Cellular and network mechanisms of rhythmic recurrent activity in neocortex. Nat. Neurosci 3, 1027-1034. [PubMed: 11017176]

Serafini T, et al. , 1996. Netrin-1 is required for commissural axon guidance in the developing vertebrate nervous system. Cell. 87, 1001-1014. [PubMed: 8978605]

Shu Y, et al. , 2003. Turning on and off recurrent balanced cortical activity. Nature. 423, 288-293. [PubMed: 12748642]

Sippy T, Yuste R, 2013. Decorrelating action of inhibition in neocortical networks. J. Neurosci 33, 9813-9830. [PubMed: 23739978]

Skarnes WC, et al. , 2011. A conditional knockout resource for the genome-wide study of mouse gene function. Nature. 474, 337-342. [PubMed: 21677750]

Sohal VS, et al. , 2009. Parvalbumin neurons and gamma rhythms enhance cortical circuit performance. Nature. 459, 698-702. [PubMed: 19396159]

Stedehouder J, et al. , 2017. Fast-spiking Parvalbumin interneurons are frequently Myelinated in the cerebral cortex of mice and humans. Cereb. Cortex 27, 5001-5013. [PubMed: 28922832]

Stedehouder J, et al. , 2019. Local axonal morphology guides the topography of interneuron myelination in mouse and human neocortex. Elife. 8 .

Szegedi V, et al. , 2017. High-precision fast-spiking basket cell discharges during complex events in the human Neocortex. eNeuro. 4.

Szegedi V, et al. , 2020. Robust perisomatic GABAergic self-innervation inhibits basket cells in the human and mouse supragranular neocortex. Elife. 9.

Tikhonova TB, et al. , 2018. Cell type- and layer-specific muscarinic potentiation of excitatory synaptic drive onto Parvalbumin neurons in mouse prefrontal cortex. eNeuro. 5.

Tsantoulas C, et al. , 2012. Sensory neuron downregulation of the Kv9.1 potassium channel subunit mediates neuropathic pain following nerve injury. J. Neurosci 32, 17502-17513. [PubMed: 23197740] 
Uhlhaas PJ, Singer W, 2010. Abnormal neural oscillations and synchrony in schizophrenia. Nat. Rev. Neurosci 11, 100-113. [PubMed: 20087360]

Uhlhaas PJ, Singer W, 2015. Oscillations and neuronal dynamics in schizophrenia: the search for basic symptoms and translational opportunities. Biol. Psychiatry 77, 1001-1009. [PubMed: 25676489]

Voss AK, et al. , 1998. Efficiency assessment of the gene trap approach. Dev. Dyn 212, 171-180. [PubMed: 9626493]

Wang B, et al. , 2016. Firing frequency maxima of fast-spiking neurons in human, monkey, and mouse Neocortex. Front. Cell. Neurosci 10, 239. [PubMed: 27803650]

Whittington MA, et al. , 2000. Inhibition-based rhythms: experimental and mathematical observations on network dynamics. Int. J. Psychophysiol 38, 315-336. [PubMed: 11102670]

Yanagi M, et al. , 2014. Kv3.1-containing $\mathrm{K}(+)$ channels are reduced in untreated schizophrenia and normalized with antipsychotic drugs. Mol. Psychiatry 19, 573-579. [PubMed: 23628987]

Yeo TT, et al. , 1997. Deficient LAR expression decreases basal forebrain cholinergic neuronal size and hippocampal cholinergic innervation. J. Neurosci. Res 47, 348-360. [PubMed: 9039657]

Zucca S, et al. , 2017. An inhibitory gate for state transition in cortex. Elife. 6. 

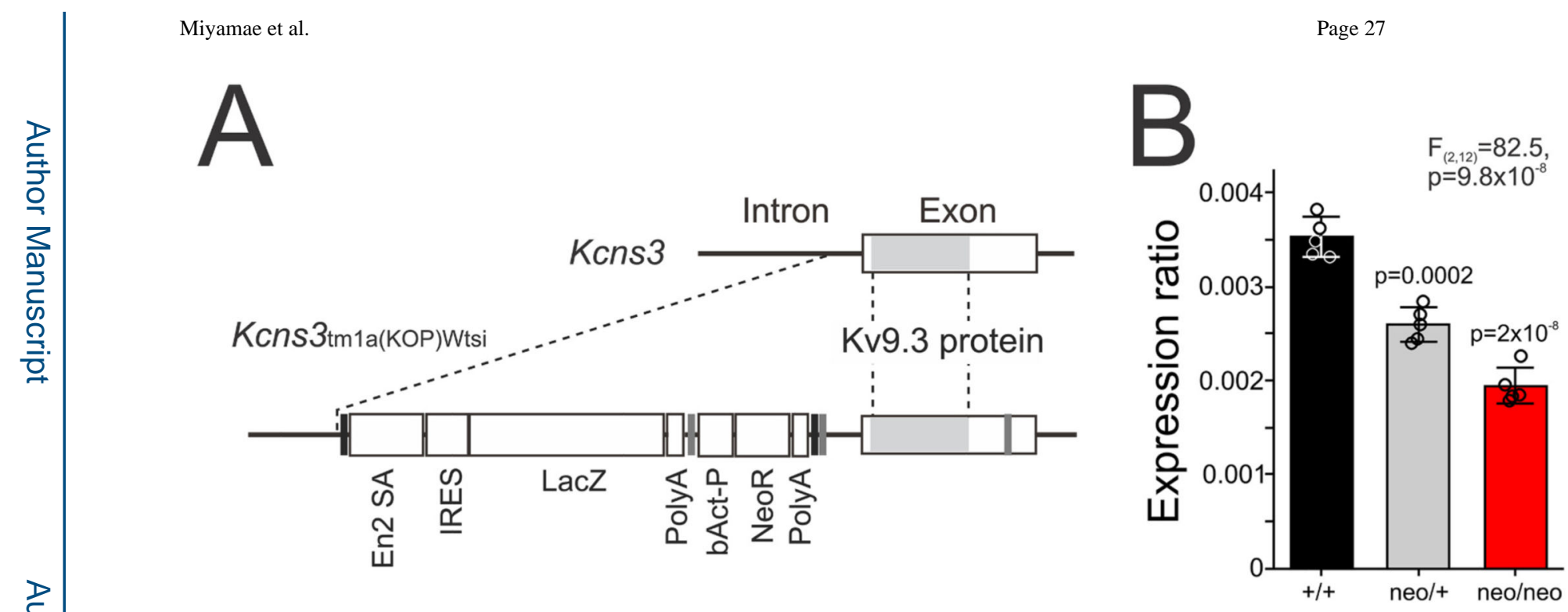

Fig. 1.

Gene trapping of Kcns3. A) The structure around the only protein-coding exon of wild type

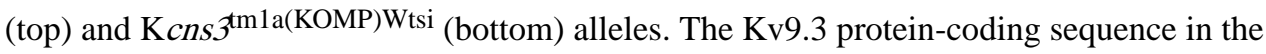
exon is indicated by the shaded region. Broken lines connect the equivalent positions in both alleles. Vertical black lines: FRT sites, Vertical gray lines: loxP sites, En2SA: mouse En2 splicing acceptor site, IRES: Internal ribosomal entry site, LacZ; beta-galatosidase gene, Poly-A: SV40 polyadenylation sites, bAct-P: human $\beta$-actin promoter, NeoR: Neomycin resistance gene. B) Bar graphs summarizing the mean \pm SEM expression levels of Kcns3 mRNA in the frontal cortex of $K c n s 3^{+/+}, K c n s 3^{\text {neo/+ }}$ and $K c n s 3^{\text {neo/neo }}$ mice ( $n=5$ per genotype) measured by real-time quantitative PCR (qPCR). Expression levels were ratios against the geometric mean of three internal control transcripts. The data of individual mice are presented by open circles superimposed over each bar. The $\mathrm{F}$ and $p$ values reported are from One-way analysis of variance (ANOVA). $P$ values of Tukey post-hoc comparisons versus $\mathrm{Kcns}^{+/+}$mice are shown above each bar for $K c n s 3^{\text {neo/+ }}$ and $K c n s 3^{\text {neo/neo }}$ mice. 

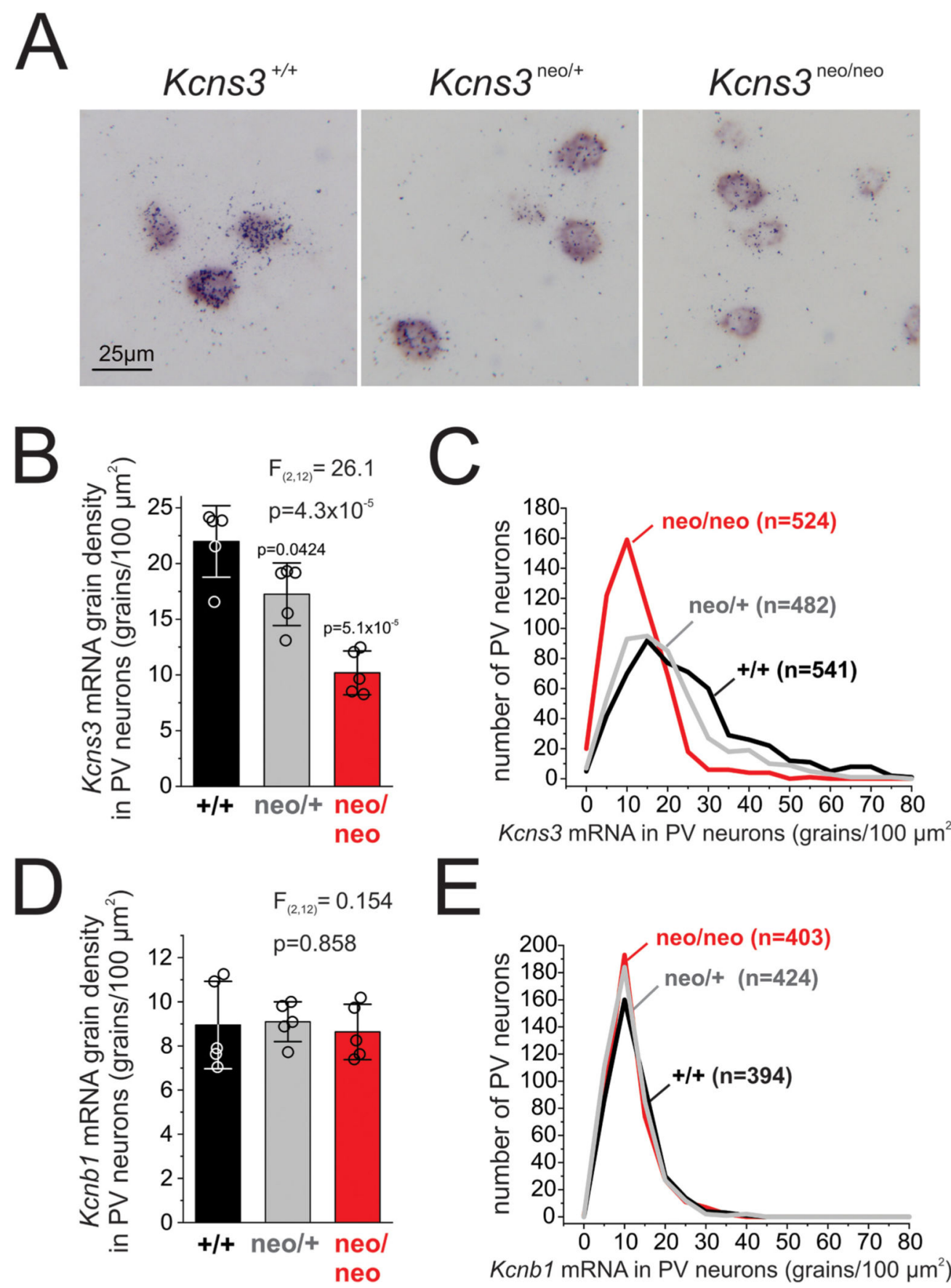

Fig. 2.

Gene expression in parvalbumin-positive (PV) neurons from Kcns3-deficient mice. A) Representative photomicrographs of frontal cortex from $\mathrm{Kcns}^{3^{+/+}}, \mathrm{Kcns} 3^{\text {neo/+ }}$ and $K c n s 3^{\text {neo/neo }}$ mice showing expression of $P V a l b$ mRNA (detected as the color reaction product by the digoxigenin-labeled riboprobe), and Kcns3 mRNA (detected as silver grain accumulation by the ${ }^{35} \mathrm{~S}$-labeled riboprobe). B) Bar graphs summarizing the mean $\pm \mathrm{SEM}$ $K c n s 3$ grain density per PV cell (grains/100 $\mathrm{m}^{2}$ ) in frontal cortex of $K c n s 3^{+/+}, K c n s 3^{\text {neo/+ }}$ and $K c n s 3^{\text {neo/neo }}$ mice $(\mathrm{n}=5$, each genotype). The data of individual mice are presented by 
open circles superimposed over each bar. The $\mathrm{F}$ and $p$ values reported are from One-way analysis of variance (ANOVA). P values of Tukey post-hoc comparisons versus $\mathrm{Kcns}^{+/+}$ mice are shown above each bar for Kcns $3^{\text {neo/+ }}$ and Kcns $3^{\text {neo/neo }}$ mice. C) Histograms of distribution of Kcns3 mRNA grain density per PV cell. D) Bar graphs summarizing the mean \pm SEM Kcnb1 mRNA grain density per PV cell (grains $/ 100 \mu \mathrm{m}^{2}$ ) in frontal cortex of $\mathrm{Kcns}^{+/+}, K c n s 3^{\text {neo/+ }}$ and $K c n s 3^{\text {neo/neo }}$ mice ( $\mathrm{n}=5$, each genotype). The data of individual mice are presented by open circles superimposed over each bar. The $\mathrm{F}$ and $\mathrm{p}$ values reported are from One-way ANOVA. E) Histograms of distribution of Kcnb1 mRNA grain density per PV cell. 

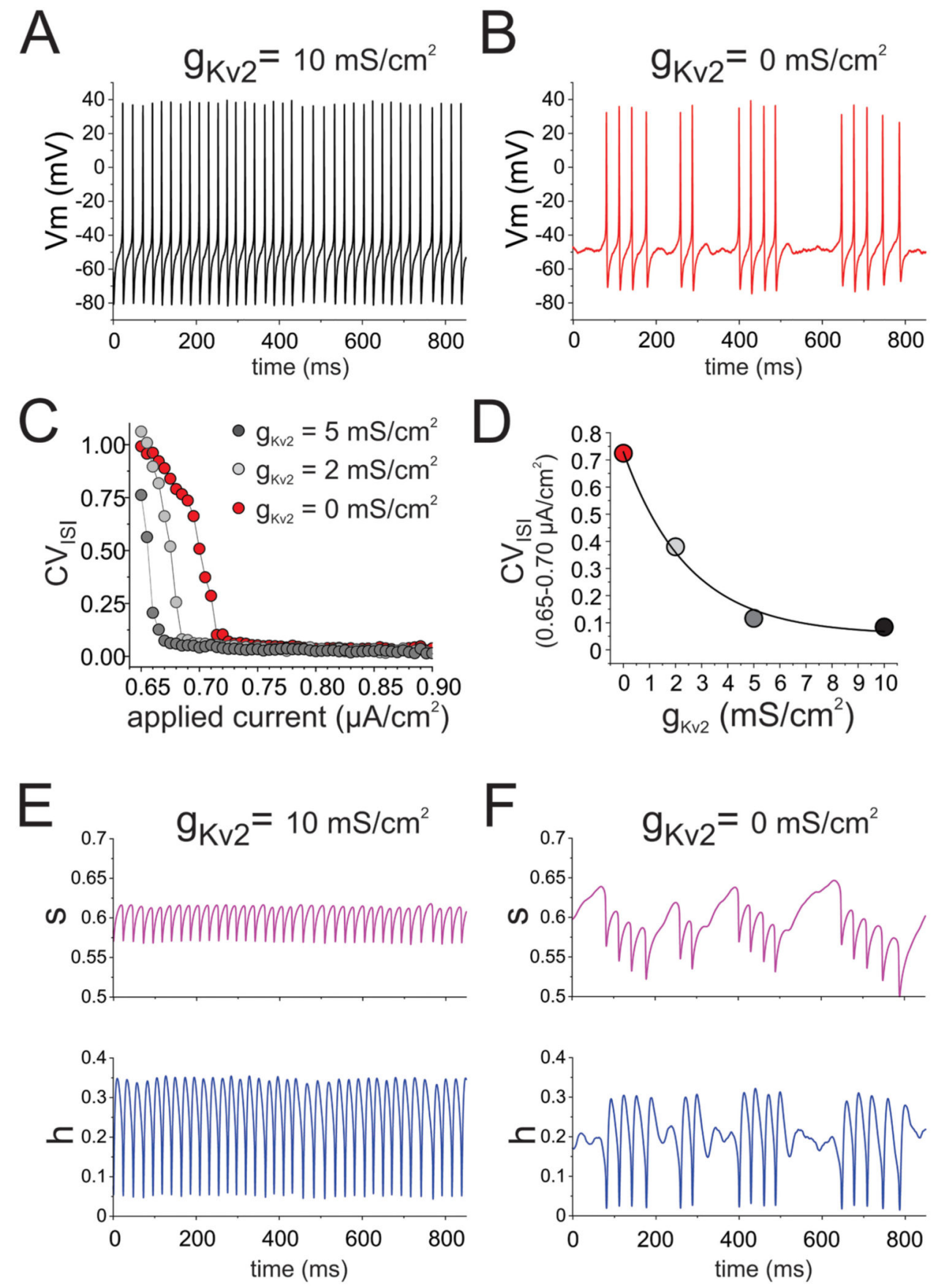

Fig. 3.

Simulations in a fast spiking (FS) cell model assessing the effect of reduced Kv2.1 conductance on the FS cell properties. A) Spike train evoked in the model FS cell with $\mathrm{Kv} 2.1$ conductance $\left(\mathrm{g}_{\mathrm{Kv} 2}\right)$ intact. B) Spike train evoked in the model FS cell without $\mathrm{g}_{\mathrm{Kv} 2}$. C) Plots of the coefficient of variation of the inter spike interval ( $\left.\mathrm{CV}_{\text {ISI }}\right)$ in spike trains as a function of applied current for the model FS cell with intact and reduced levels of $\mathrm{g}_{\mathrm{Kv} 2}$. D) Graph of $\mathrm{CV}_{\mathrm{ISI}}$ in spike trains evoked by applied currents (averaged for $0.65-0.70$ $\mu \mathrm{A} / \mathrm{cm}^{2}$ ) in the model cell with intact and reduced levels of $\mathrm{g}_{\mathrm{Kv2}}$. E) Time course of the 
Hodgkin-Huxley inactivation gating variables $\mathrm{s}$ (top) and $\mathrm{h}$ (bottom) for the FS cell model with intact Kv2, during the spike train shown in A). F) Time course of the Hodgkin-Huxley inactivation gating variables $\mathrm{s}$ (top) and $\mathrm{h}$ (bottom) for the FS cell model with reduced Kv2, during the spike train shown in $\mathrm{B}$ ). 


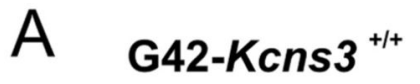

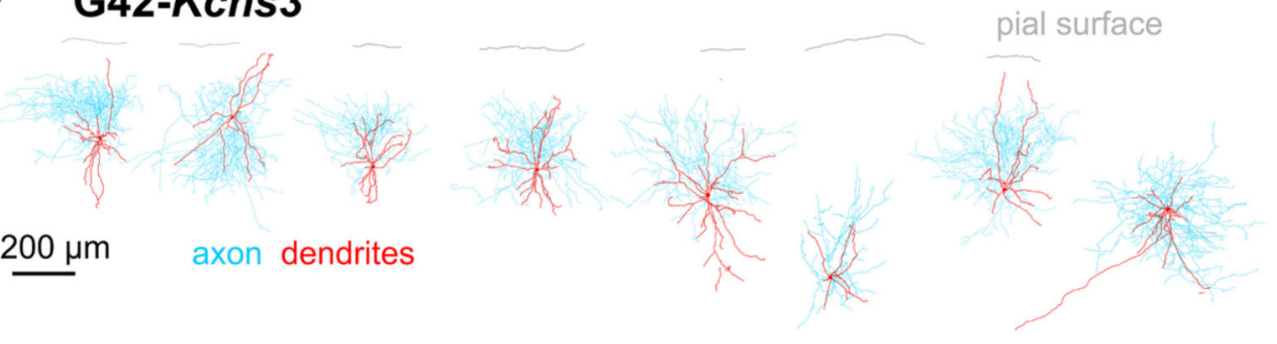

B $\quad$ G42-Kcns $3^{\text {neo/neo }}$
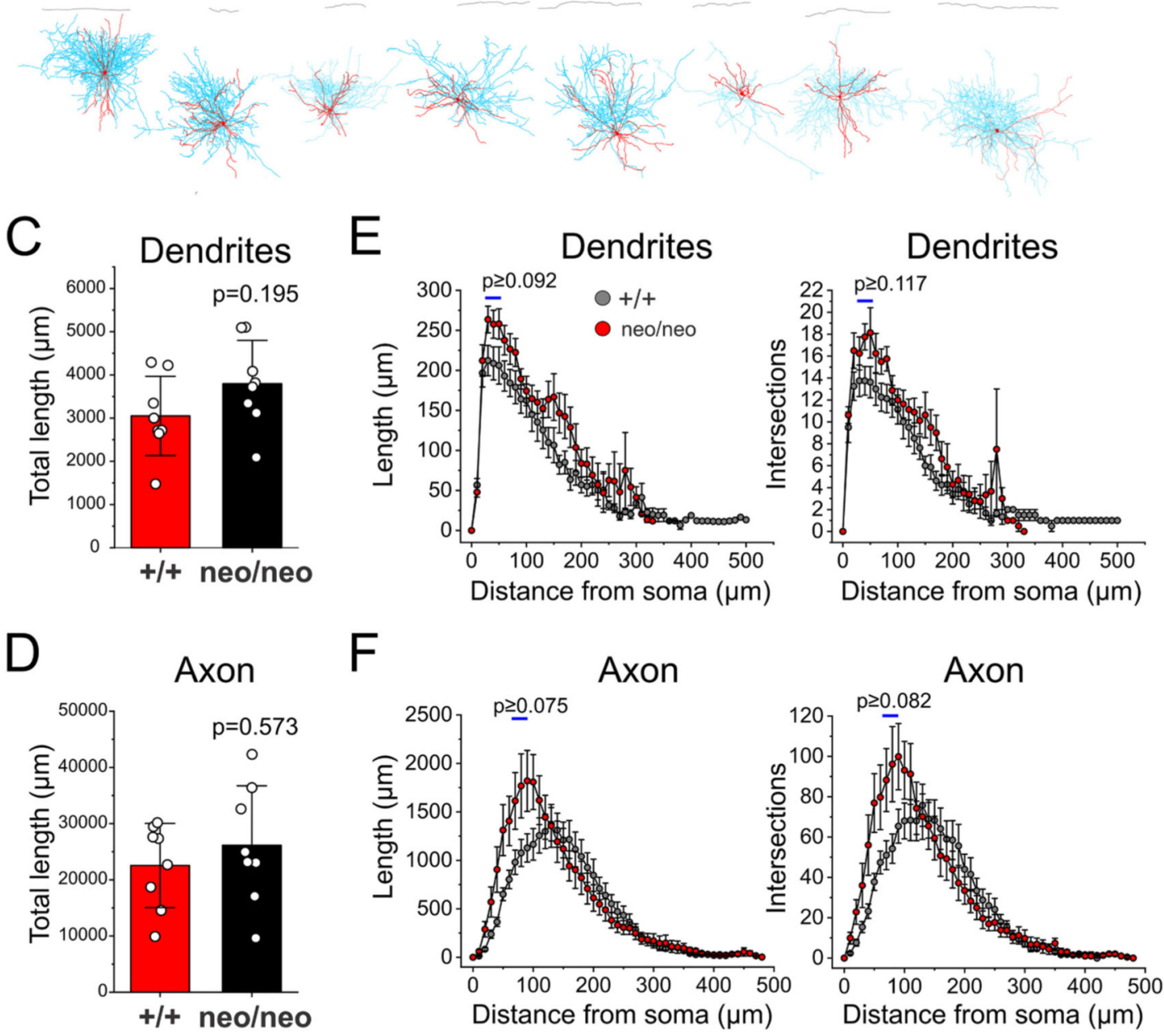

Fig. 4.

Morphology of the parvalbumin-positive (PV) neurons studied in prefrontal cortex slices from G42-Kcns $3^{+/+}$and G42-Kcns $3^{\text {neo/neo }}$ mice. A) Digital reconstructions ( $n=8$ cells from 5 mice) of PV basket cells (PVBCs) recorded in slices from $\mathrm{G} 42-\mathrm{Kcns}^{+/ /+}$mice. B) Digital reconstructions ( $\mathrm{n}=8$ cells from 5 mice) of PVBCs recorded in slices from G42-Kcns $3^{\text {neo/neo }}$ mice. Calibration bar and labels apply to both A) and B). C) Bar graph displaying the total length of the dendritic tree of PVBCs from G42-Kcns $3^{+/+}(\mathrm{n}=8$ cells from 5 mice) and G42-Kcns $3^{\text {neo/neo }}$ mice ( $\mathrm{n}=8$ cells from 5 mice). Shown here, and in 
D), are the $p$ values from Mann- Whitney tests performed after Shapiro-Wilk tests of the residuals produced $p<0.05$ for both the original data and the Ln-transformed data. D) Bar graph displaying the total length of the axonal arbor of PVBCs from G42-Kcns $3^{+/+}$ and G42-Kcns $3^{\text {neo/neo }}$ mice, same cells as in C). E) Plots of dendrite length (left panel) and number of intersections (right panel) from Sholl analysis of the same neurons in C). Shown here, and in F), are the smallest $\mathrm{p}$ values from $t$-test comparisons done for the three Sholl compartments with largest differences between genotypes, indicated by horizontal bars. F) Plots of axon length (left panel) and number of intersections (right panel) from Sholl analysis of the same neurons in $\mathrm{C}$ ). 

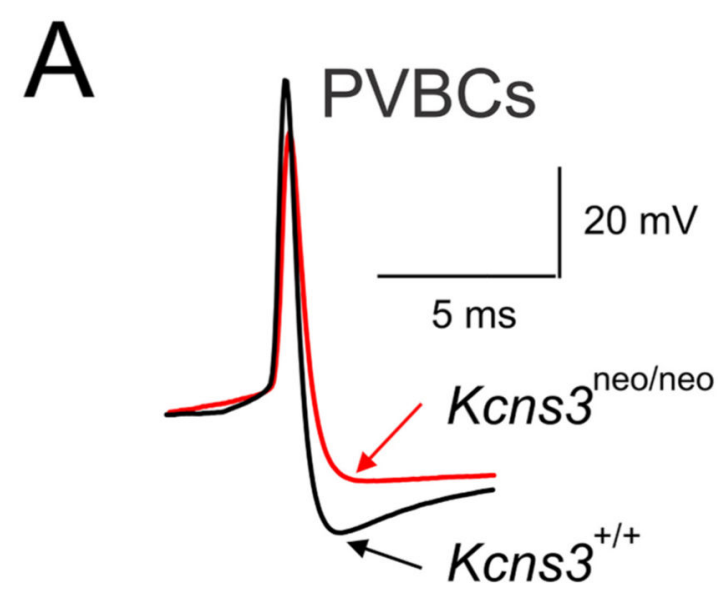

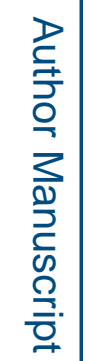

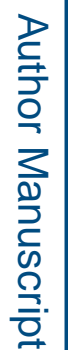
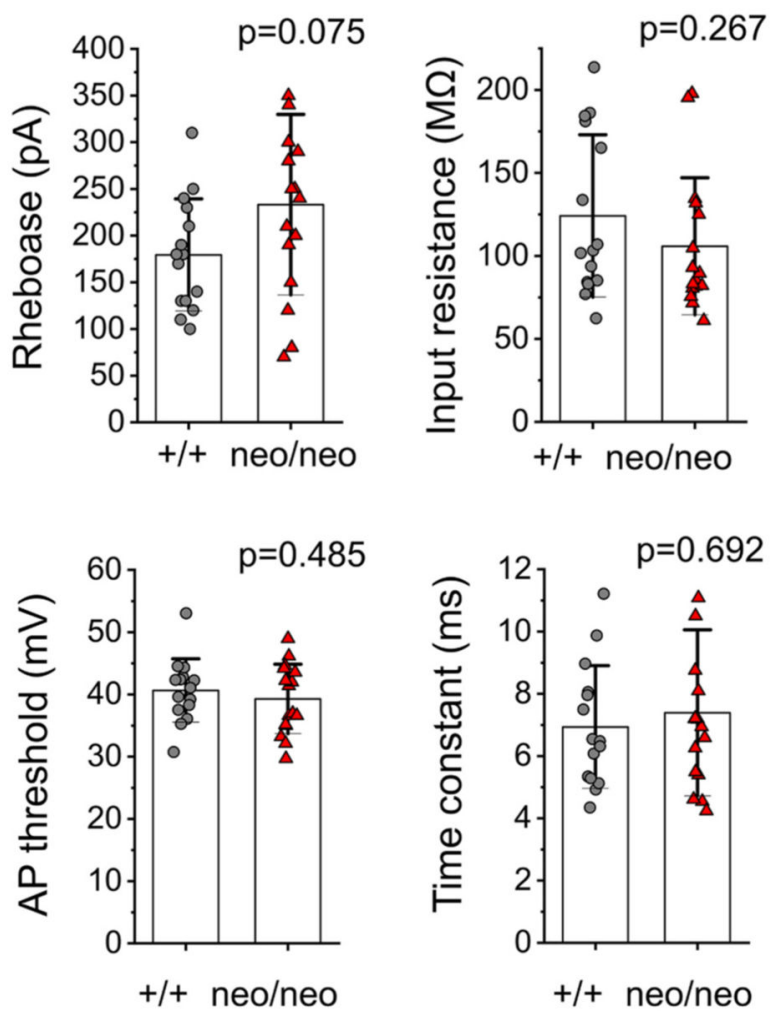
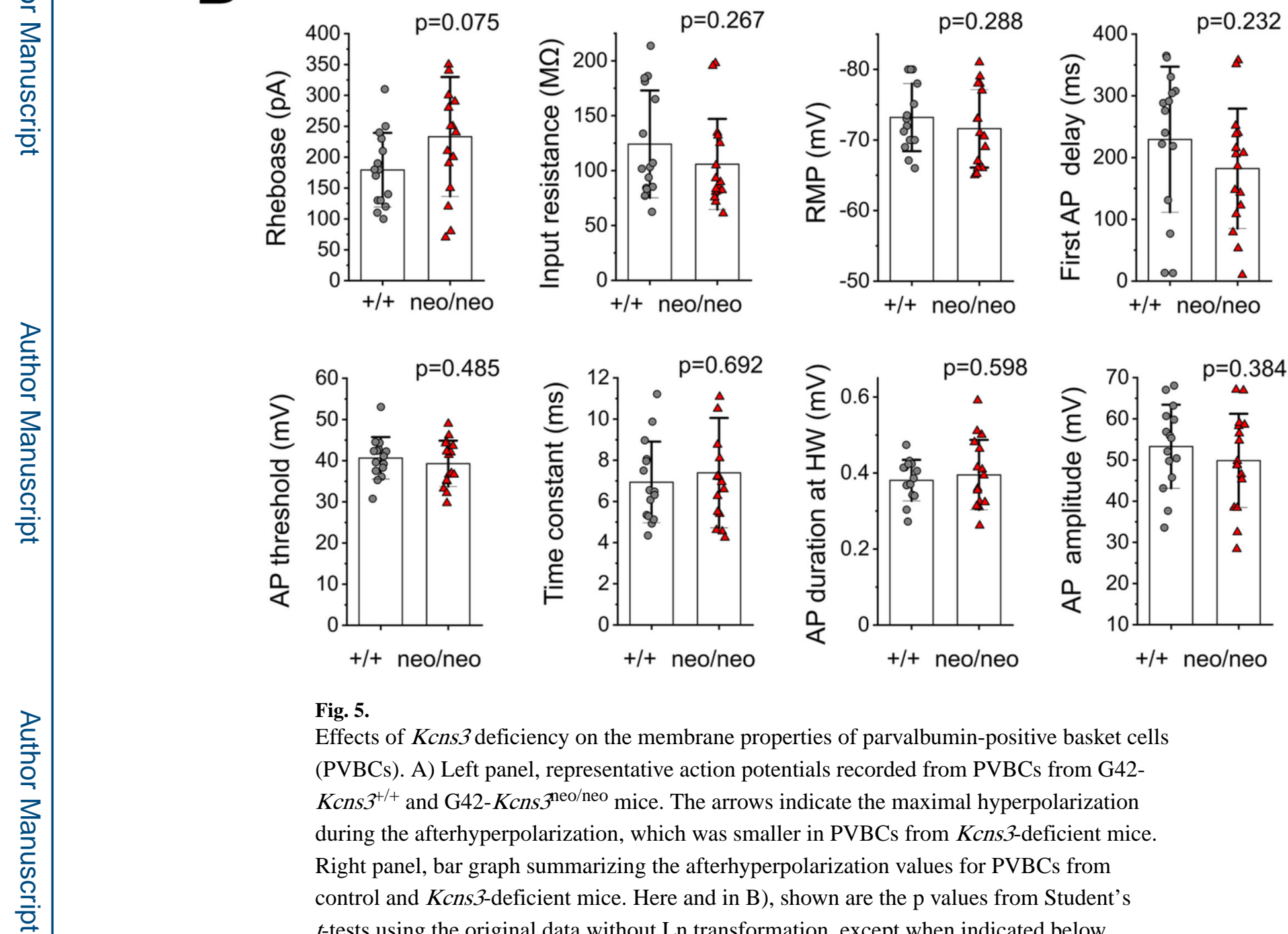

Fig. 5.

Effects of Kcns3 deficiency on the membrane properties of parvalbumin-positive basket cells (PVBCs). A) Left panel, representative action potentials recorded from PVBCs from G42$\mathrm{Kcns}^{\mathrm{H}^{+/}}$and G42-Kcns $3^{\text {neo/neo }}$ mice. The arrows indicate the maximal hyperpolarization during the afterhyperpolarization, which was smaller in PVBCs from Kcns3-deficient mice. Right panel, bar graph summarizing the afterhyperpolarization values for PVBCs from control and Kcns3-deficient mice. Here and in B), shown are the p values from Student's $t$-tests using the original data without $\mathrm{Ln}$ transformation, except when indicated below. 
B) Membrane properties of PVBCs. The measured parameters are defined as follows, Rheobase: current threshold to fire at least one action potential (AP); RMP: resting membrane potential; First AP delay: delay to fire the first AP with rheobase current stimulation; AP threshold: voltage threshold to fire an AP; Time constant: membrane time constant; AP amplitude: voltage between AP threshold and AP peak; AP duration at HW: width of the AP at half maximal amplitude. For RMP, the Shapiro-Wilk test $\mathrm{p}$ values were 0.031 for original data and 0.04 for Ln-transformed data, thus comparison was done using Mann-Whitney's test. For Rin, the Shapiro-Wilk test $\mathrm{p}$ values were 0.002 for original data and 0.055 for Ln-transformed data. For the membrane time constant, Shapiro-Wilk test p values were 0.03 for original data and 0.63 for $\mathrm{Ln}$ - transformed data. Thus differences in Rin and membrane time constant between group means were tested using Student's t-test after Ln transformation. 
A
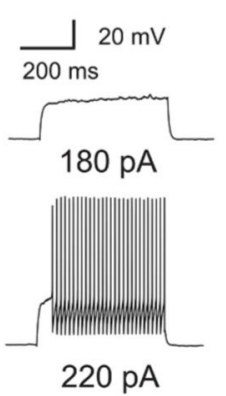

B
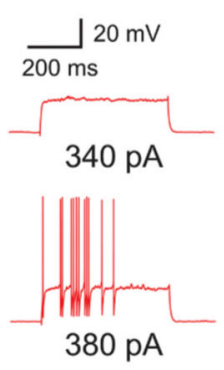

weak stuttering
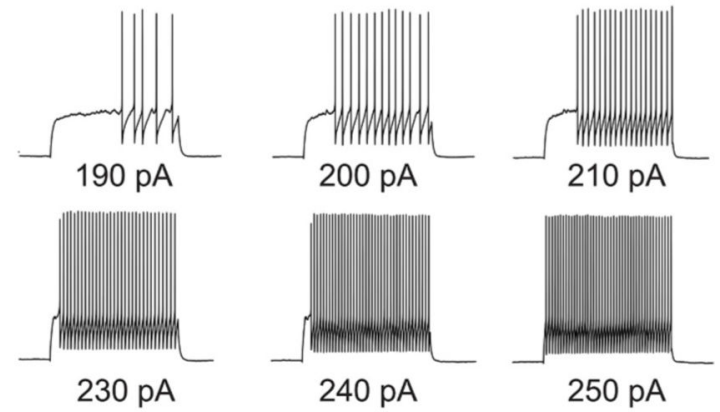

strong stuttering
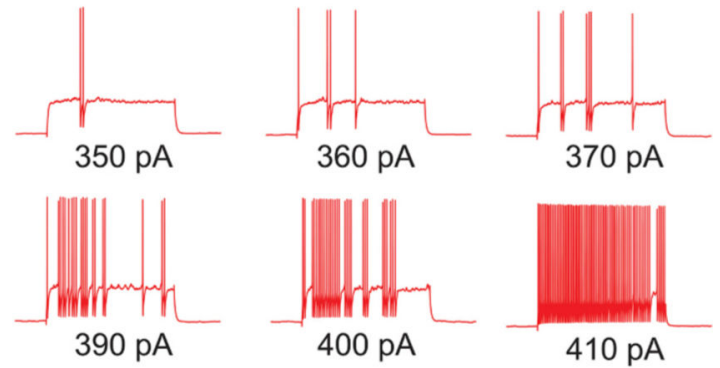

Fig. 6.

A) Representative spike trains evoked by injection of depolarizing current steps into a weak stuttering PVBC in the prefrontal cortex (PFC) of a G42-Kcns $3^{+/+}$mouse. B) Representative spike trains evoked by injection of depolarizing current steps into a PV cell with strong stuttering phenotype in PFC of a G42-Kcns $3^{\text {neo/neo }}$ mouse. 


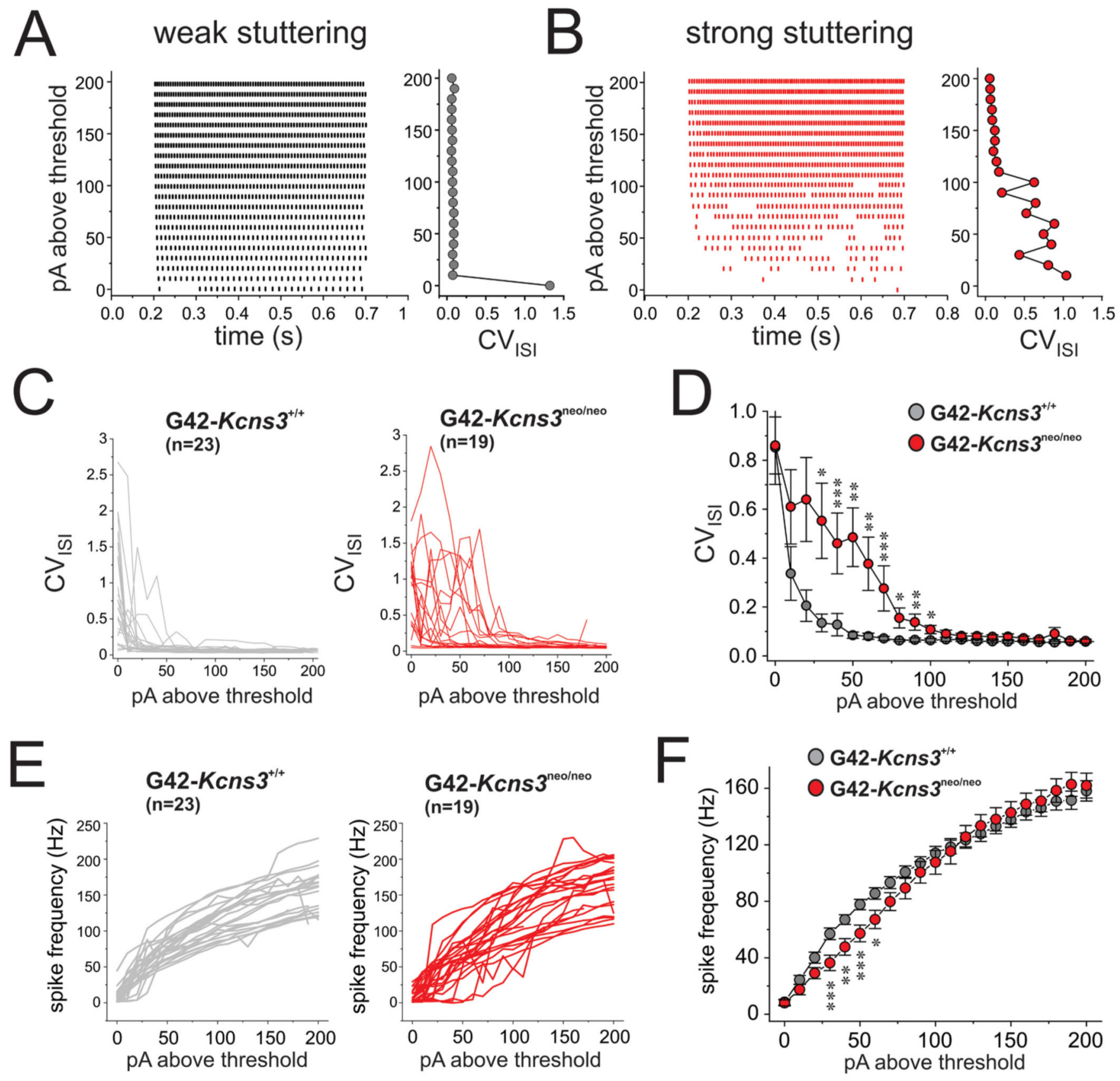

Fig. 7.

Effects of Kcns3 deficiency on the variability of inter spike intervals (ISIs) in spike trains evoked by injection of current steps. A) Left panel, representative raster plot for spike trains evoked in a weak stuttering parvalbumin-positive basket cell (PVBC) in the prefrontal cortex (PFC) of a G42-Kcns $3^{+/+}$mouse. Right panel, coefficient of variation of ISIs (CV ISI) (Xaxis) graphed as a function of stimulus current above threshold (Y-axis). B) Representative raster plot and $\mathrm{CV}_{\text {ISI }}$ graph as in $\mathrm{A}$ ), but for spike trains evoked in a strong stuttering PVBC in PFC of a G42-Kcns $3^{\text {neo/neo }}$ mouse. C) Graphs of $\mathrm{CV}_{\text {ISI }}$ as a function of stimulus current above threshold for each of the PVBCs of G42-Kcns $3^{+/+}$(left, $n=23$ cells from 
11 mice) and G42-Kcns $3^{\text {neo/neo }}$ mice (right, $n=19$ cells from 8 mice). D) Graphs of $\mathrm{CV}_{\text {ISI }}$ (mean $\pm \mathrm{SEM}$ ) as a function of stimulus current above threshold for the PVBCs of G42-Kcns $3^{+/+}$and G42-Kcns $3^{\text {neo/neo }}$ mice displayed in C). Shapiro-Wilk tests of the original data produced $\mathrm{p}$ values $\varangle 0.05$ at all current levels $0-130 \mathrm{pA}$ above threshold and $\mathrm{p}$ values $<0.05$ with Ln-transformed data at all current levels above threshold except 10 , 20,30 and 40 pA. Hence, we employed Mann-Whitney's tests. *: $p<0.02, * *: p<0.01$, $* * *: p<0.005$. E) Left, graphs of mean spike frequency per current step as a function of stimulus current above threshold for each of the PVBCs of G42-Kcns $3^{+/+}$(left, $n=23$ cells from 11 mice) and G42-Kcns $3^{\text {neo/neo }}$ (right, $\mathrm{n}=19$ cells from 8 mice) mice. F) Graphs of spike frequency (mean \pm SEM) as a function of stimulus current above threshold for PVBCs of G42-kcns $3^{+/+}$and G42-kcns $3^{\text {neo/neo }}$ mice. For most comparisons at current levels $0-100 \mathrm{pA}$ above threshold, Shapiro-Wilk tests produced $\mathrm{p}$ values $\varangle 0.05$ with original and Ln-transformed data, hence Mann-Whitney's tests were employed. *: p <0.02, **: p <0.01, $* * *$ : $<0.005$. 


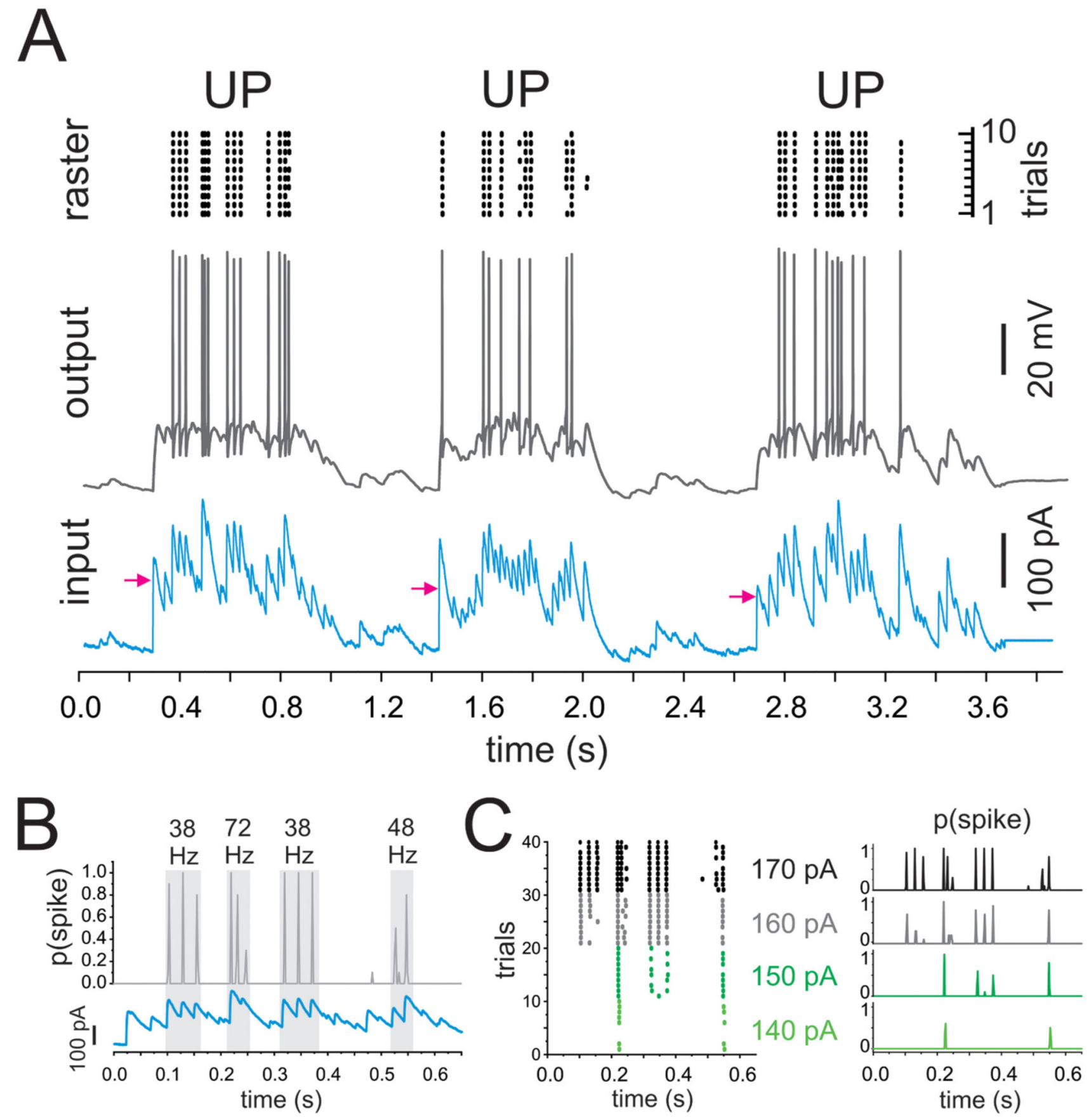

Fig. 8.

The current injection paradigm employed to assess the effects of Kcns3 deficiency on the response of PVBCs to UP states-like stimuli. A) The traces at the bottom (input) show the injected depolarizing current mimicking synaptic input during three UP states $\left(\mathrm{UP}_{(1)}, \mathrm{UP}_{(2)}\right.$, and $\left.\mathrm{UP}_{(3)}\right)$ with two intermediate DOWN states. The arrows represent the mean injected current obtained by averaging the current injected across the duration of each UP state. Traces in the middle (output) show the spike output evoked in a parvalbumin-positive basket cell (PVBC) by the UP state current injection. The raster plots at the top were obtained 
from the spike trains evoked in the PVBC by 10 repetitions of the UP state current injection at stimulus strength 4 in 10 consecutive trails. B) The top graph shows the average spike probability, $\mathrm{p}$ (spike), computed in $2 \mathrm{~ms}$ bins throughout the injection of $\mathrm{UP}_{(1)}$ repeated ten times at the stimulus strength 4 . The bottom graph shows the depolarizing current injected during $\mathrm{UP}_{(1)}$. The gray rectangles indicate the time windows of bursts of gamma band activity, with frequency measured from the intervals between subsequent peaks of $\mathrm{p}$ (spike). C) Left, raster plots from spike trains evoked by injection into a PVBC of $\mathrm{UP}_{(1)}$ at stimulus strengths 1 to 4 (the mean injected current during $\mathrm{UP}_{(1)}$ was $140,150,160$ and $170 \mathrm{pA}$ in this example). Right, spike probability $\mathrm{p}$ (spike) computed from the raster plots in the left panel. 


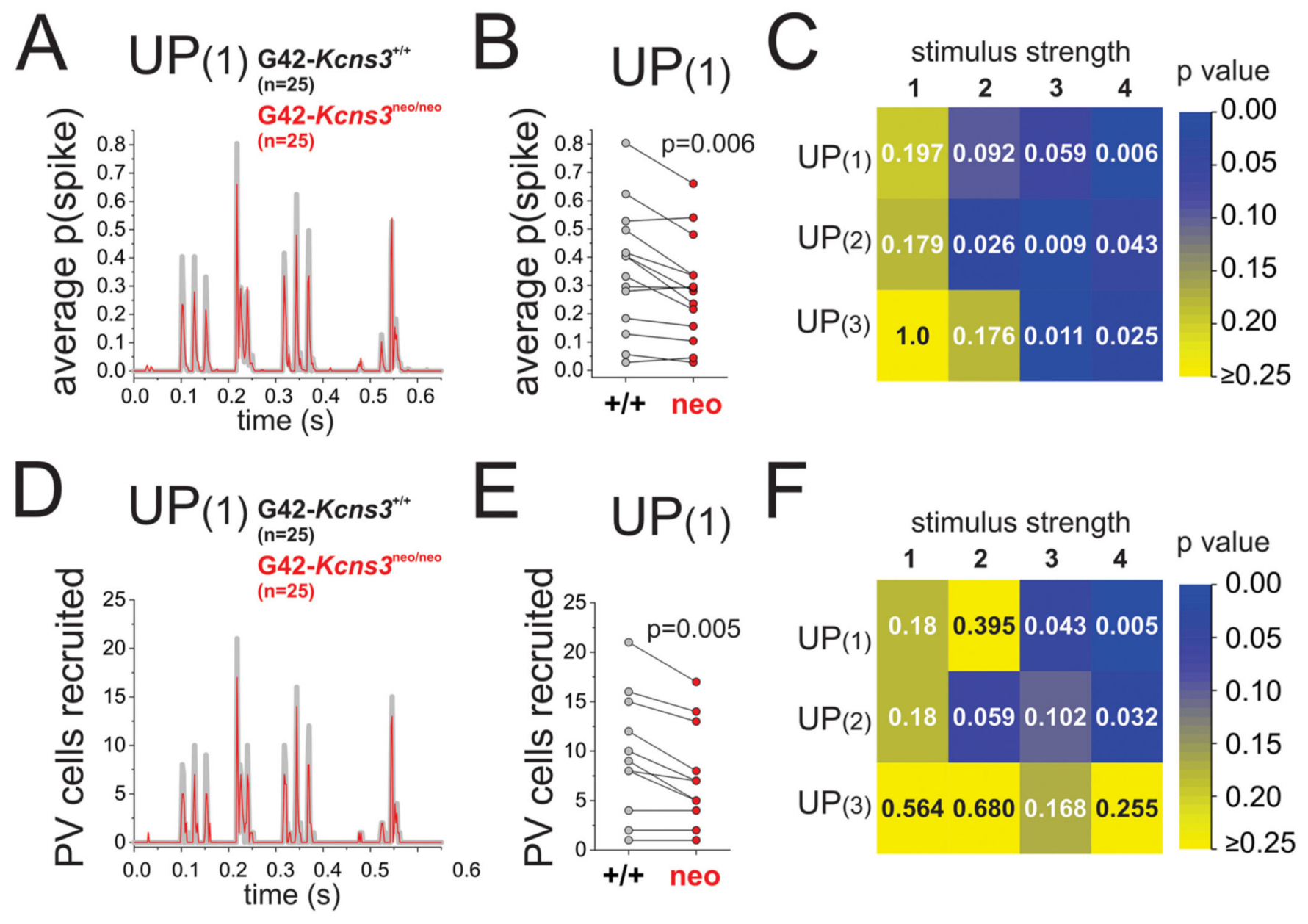

Fig. 9.

Effects of Kcns3 deficiency on the spike output of parvalbumin-positive basket cells (PVBCs) during UP states. A) Curves of mean spike probability, $\mathrm{p}\left(\right.$ spike), during $\mathrm{UP}_{(1)}$ at stimulus strength 4 , computed by averaging $\mathrm{p}$ (spike) across 25 cells from $15 \mathrm{G} 42-\mathrm{Kcns}^{+/+}$ mice and 25 cells from 14 G42-Kcns $3^{\text {neo/neo }}$ mice. B) Paired comparison of $\mathrm{p}$ (spike) for the corresponding peaks of spike probability depicted in A). C) Matrix plot showing the $\mathrm{p}$ values of paired comparisons for matching peaks of $\mathrm{p}$ (spike) between G42-kcns $3^{+/+}$and G42-kcns $3^{\text {neo/neo }}$ mice during injection of $\mathrm{UP}_{(1)}, \mathrm{UP}_{(2)}$ and $\mathrm{UP}_{(3)}$ at stimulus strengths 1-4. For most combinations of UP state and stimulus strength, Shapiro-Wilk analysis produced $\mathrm{p}$ values $<0.05$ with the original and the Ln-transformed data. Hence, here and in B), we report the $\mathrm{p}$ values of Wilcoxon Signed Rank tests. D) Curves of the number of PVBCs recruited by a single presentation of $\mathrm{UP}_{(1)}$ at stimulus strength 4 , computed for the 25 cells from G42$\mathrm{Kcns}^{+/+}$and 25 cells from G42-Kcns $3^{\text {neo/neo }}$ mice. E) Paired comparison of the number of PVBCs recruited by a single presentation of $U_{(1)}$ for the matching peaks depicted in D). F) Matrix plot showing the $\mathrm{p}$ values of paired comparisons for matching peaks of number of PVBCs recruited among the 25 PVBCs between G42- Kcns $3^{+/+}$and G42-Kcns $3^{\text {neo/neo }}$ mice during injection of $\mathrm{UP}_{(1)}, \mathrm{UP}_{(2)}$ and $\mathrm{UP}_{(3)}$ at stimulus strengths 1-4. For most combinations of UP state and stimulus strength, Shapiro-Wilk analysis produced p values $<0.05$ with the 
original and the Ln-transformed data. Hence, here and in E), we report the p values of Wilcoxon Signed Rank tests. 


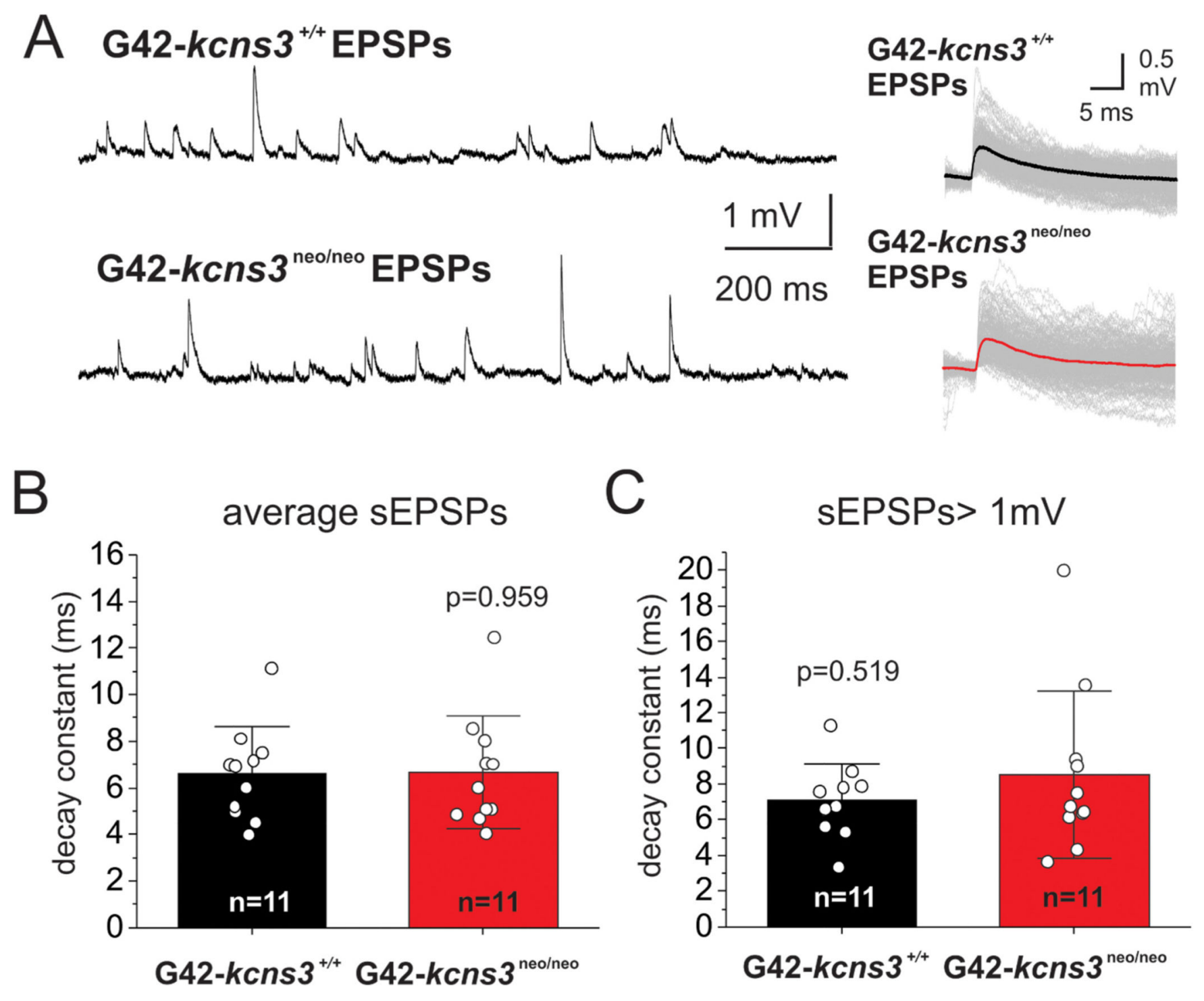

Fig. 10.

Effects of Kcns3 deficiency on excitatory inputs to parvalbumin-positive basket cells (PVBCs). A) Left panel, traces illustrating examples of sEPSPs recorded at resting membrane potential (RMP) from PVBCs in slices from G42- $\mathrm{Kcns}^{+/+}$and G42-

$K c n s 3^{\text {neo/neo }}$ mice. Right panel, examples of individual sEPSPs recorded from PVBCs of G42-Kcns $3^{+/+}$and G42-Kcns $3^{\text {neo/neo }}$ mice, aligned by their rising phase and superimposed with their averages (thick lines). B) Bar graphs illustrating the decay time constant of sEPSPs recorded from PVBCs from G42-Kcns $3^{+/+}$and G42-Kcns $3^{\text {neo/neo }}$ mice. C) Bar graphs illustrating the decay time constant of sEPSPs $>1 \mathrm{mV}$ recorded from PVBCs from G42-Kcns $3^{+/+}$and G42-Kcns $3^{\text {neo/neo }}$ mice. 


\section{롤 \\ 골}

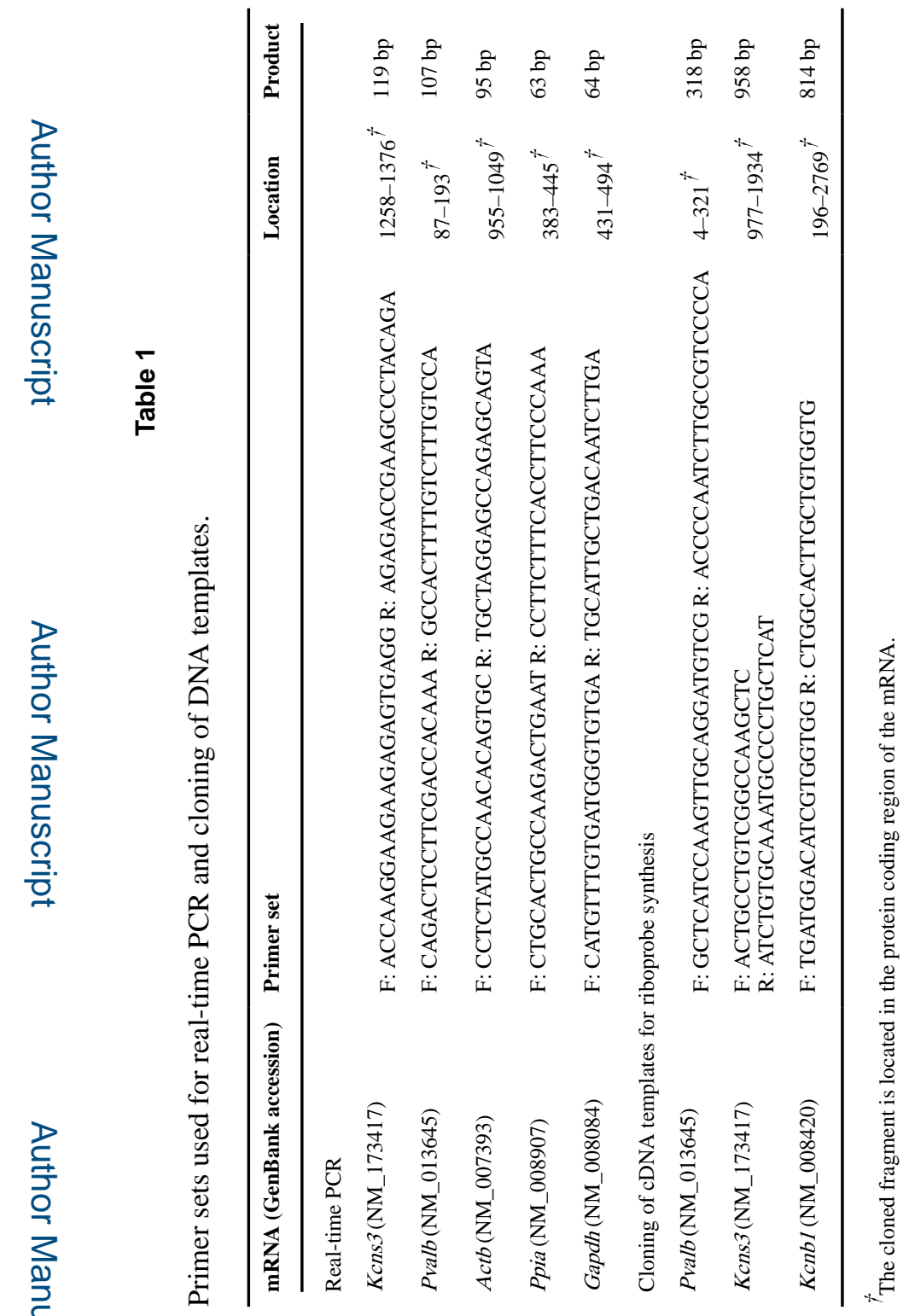



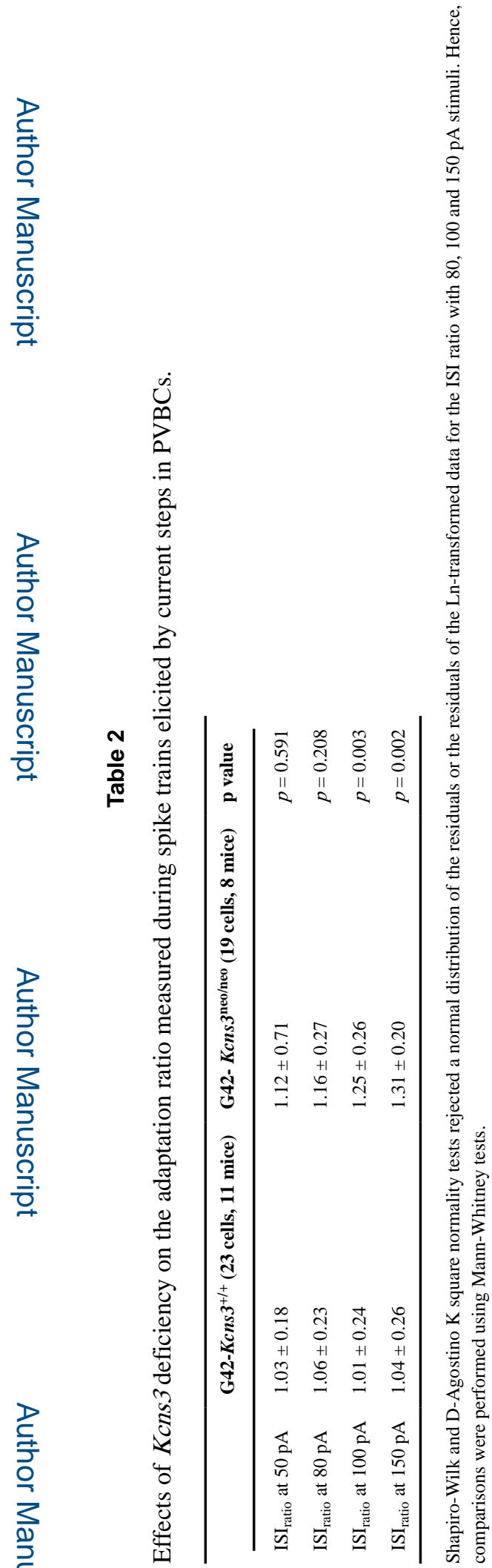

Neurobiol Dis. Author manuscript; available in PMC 2021 October 31. 